\title{
Thioether-Based Fluorescent Covalent Organic Framework for Selective Detection and Facile Removal of Mercury(II)
}

\author{
San-Yuan Ding, ${ }^{\dagger}$ Ming Dong, ${ }^{\dagger}$ Ya-Wen Wang, ${ }^{\dagger}$ Yan-Tao Chen, ${ }^{\dagger}$ Huai-Zhen Wang, ${ }^{\dagger}$ \\ Cheng-Yong $\mathrm{Su},{ }^{\ddagger}$ and Wei Wang ${ }^{*}, \uparrow$, \\ ${ }^{\dagger}$ State Key Laboratory of Applied Organic Chemistry, College of Chemistry and \\ Chemical Engineering, Lanzhou University, Lanzhou, Gansu 730000, China; \\ $\$$ School of Chemistry and Chemical Engineering, Sun Yat-Sen University, \\ Guangzhou 510275, China \\ $\S$ Collaborative Innovation Center of Chemical Science and Engineering, Tianjin \\ 300071, China \\ *E-mail: wang_wei@lzu.edu.cn
}
A Summary of Figures and Tables
B General Information
C Synthetic Procedures
D FT-IR Spectra
E UV/Vis Absorption Spectra
F Fluorescence Spectra
G The Detection Limit of COF-LZU8 with $\mathrm{Hg}^{2+}$
H Structural Modeling and Powder X-Ray Diffraction Analysis
I $\quad \mathrm{N}_{2}$ Adsorption-Desorption Analysis
J Thermogravimetric Analysis
K Scanning Electron Micrographs
L Liquid NMR Spectra
M References 


\section{A. Summary of Figures and Tables}

$\begin{array}{lll}\text { Fig. S1 FT-IR spectra of COF-LZU8, 1, 2, and the model compound } 3 & \text { S10 }\end{array}$

Fig. S2 FT-IR spectra of COF-LZU8, Hg/COF-LZU8, and $\mathrm{Hg}\left(\mathrm{ClO}_{4}\right)_{2} \quad$ S11

Fig. S3 UV-Vis spectra of COF-LZU8, 1, 2, and the model compound $3 \quad$ S12

Fig. S4 Fluorescence spectra of COF-LZU8, COF-42, and COF-LZU1 S13

Fig. S5 Time-dependent fluorescence spectra of COF-LZU8 S13

Fig. S6 Fluorescence spectra of COF-LZU8 dispersed in different solvents $\begin{array}{ll}\text { before and after the addition of } \mathrm{Hg}^{2+} & \mathrm{S} 14\end{array}$

Fig. S7 Fluorescence emission intensity against the concentration of COF-LZU8 $\quad$ S14

Fig. S8 Fluorescence spectra of COF-LZU8, COF-42, and COF-LZU1 dispersed in acetonitrile before and after the addition of $\mathrm{Hg}^{2+}$

Fig. S9 Fluorescence spectra of COF-LZU8 in the solid state upon the addition of $\mathrm{Hg}^{2+}$

Fig. S10 Fluorescence quenching of COF-LZU8 against the $\mathrm{Hg}^{2+}$ content in the solid state

Fig. S11 Linear concentration range of $\mathrm{Hg}^{2+}$ for COF-LZU8 in acetonitrile

Tab. S1 Fractional atomic coordinates for the unit cell of COF-LZU8

Fig. S12 PXRD patterns of COF-LZU8: observed and calculated (eclipsed)

Fig. S13 PXRD patterns of COF-LZU8: observed and calculated (staggered)

Fig. S14 PXRD patterns of COF-LZU8, 1, and 2

Fig. S15 PXRD patterns of COF-LZU8 and the recovered COF-LZU8

Fig. S16 PXRD patterns of COF-LZU8 after treatment in aqueous solutions with $\mathrm{pH}=3$ to 13

Fig. S17 PXRD patterns of COF-LZU8 synthesized under other conditions

Fig. S18 Langmuir surface area plot for COF-LZU8

Fig. S19 BET surface area plot for COF-LZU8

Fig. S20 Pore size distribution of COF-LZU8 calculated by the BJH method

Fig. S21 TGA data for COF-LZU8

Fig. S22 SEM images of COF-LZU8 


\section{B. General Information}

\section{Materials}

All reagents, unless otherwise noted, were purchased from commercial sources and used without further purification. Dioxane, acetone, acetonitrile, and acetic acid were purified through the standard procedures.

\section{Instrumentation}

Liquid ${ }^{1} \mathrm{H}$ and ${ }^{13} \mathrm{C}$ NMR spectra were collected on a Bruker Avance III $400 \mathrm{MHz}$ NMR spectrometer using tetramethylsilane (TMS) as an internal standard.

Elemental analysis was carried out on an Elementar Analysensysteme GmbH VarioEL V3.00 elemental analyzer.

FT-IR spectra were recorded with a Nicolet NEXUS 670 instrument.

Powder X-ray diffraction (PXRD) data were collected with a PANalytical X'Pert Pro diffractometer operated at $40 \mathrm{kV}$ and $40 \mathrm{~mA}$ with $\mathrm{Cu} \mathrm{K} \alpha$ radiation (step size: $0.017^{\mathrm{o}}$, step time: $\left.10.34 \mathrm{~s}\right)$.

Solid-state NMR experiments were performed on a Bruker WB Avance II 400 MHz NMR spectrometer. The ${ }^{13} \mathrm{C}$ CP/MAS NMR spectra were recorded with a 4-mm double-resonance MAS probe and with a sample spinning rate of $10.0 \mathrm{kHz}$; a contact time of $2 \mathrm{~ms}$ (ramp 100) and a pulse delay of $3 \mathrm{~s}$ were applied.

The nitrogen adsorption and desorption isotherms were measured at $77 \mathrm{~K}$ using a Micromeritics ASAP 2020M system. The samples were outgassed at $120{ }^{\circ} \mathrm{C}$ for $8 \mathrm{~h}$ before the measurements. Surface areas were calculated from the adsorption data using Langmuir and Brunauer-Emmett-Teller (BET) methods, respectively. The pore-size-distribution curves were obtained via the non-local density functional theory (NLDFT) and the Barrett-Joyner-Halenda (BJH) method.

Field emission scanning electron microscopy (SEM) observations were performed on a Hitachi S-4800 microscope operated at an accelerating voltage of $5.0 \mathrm{kV}$.

The thermal properties of COF-LZU8 material were evaluated using a STA PT1600 Linseis thermogravimetric analysis (TGA) instrument over the temperature range of 25 to $800{ }^{\circ} \mathrm{C}$ under nitrogen atmosphere with a heating rate of $10{ }^{\circ} \mathrm{C} / \mathrm{min}$. 
X-ray photoelectron spectroscopy (XPS) data were obtained with an ESCALab210 VG Scientific electron spectrometer using 300 W Mg Ka radiation. The binding energies were referenced to the $C_{1 \mathrm{~s}}$ line at $285.0 \mathrm{eV}$ from the adventitious carbon.

The mercury contents were determined by inductively coupled plasma (ICP) analysis with an IRIS Advantage instrument. The trace contents of mercury were determined with an AFS-9800 atomic fluorescence spectrometer.

Fluorescence spectra were recorded at room temperature using a Hitachi F-7000 spectrophotometer with a PMT voltage of $700 \mathrm{~V}$ and a scan speed of $1200 \mathrm{~nm} / \mathrm{min}$; the slit width for both excitation and emission was $5 \mathrm{~nm}$. The time-dependent fluorescence spectra (Figure S5) recorded for COF-LZU8 dispersed in acetonitrile indicated that COF-LZU8 does not show any photo-bleaching. The fluorescent quantum yields were measured on an FLS920 spectrometer from Edinburgh Instruments, using the method ${ }^{1}$ for measuring the absolute photoluminescence quantum yield.

Stock solutions $(1.0 \mathrm{mM})$ of the perchlorate salts of $\mathrm{Hg}^{2+}, \mathrm{Li}^{+}, \mathrm{Na}^{+}, \mathrm{K}^{+}, \mathrm{Ag}^{+}, \mathrm{Mg}^{2+}$, $\mathrm{Ca}^{2+}, \mathrm{Ba}^{2+}, \mathrm{Al}^{3+}, \mathrm{Pb}^{2+}, \mathrm{Cu}^{2+}, \mathrm{Fe}^{2+}, \mathrm{Fe}^{3+}, \mathrm{Co}^{2+}, \mathrm{Ni}^{2+}, \mathrm{Zn}^{2+}, \mathrm{Sr}^{2+}$, and $\mathrm{Cd}^{2+}$ were prepared in ethanol; and the stock solutions $(1.0 \mathrm{mM})$ of $\mathrm{S}^{2-}$ was prepared in deionized water using $\mathrm{Na}_{2} \mathrm{~S}$. Stock solution of COF-LZU8 $(0.3 \mathrm{mg} / \mathrm{mL})$ was prepared by dispersion ${ }^{2}$ of COF-LZU8 in acetonitrile. The uniformly dispersed COF-LZU8 has the average particle size of $\sim 250 \mathrm{~nm}$ as demonstrated by the SEM images (Figure S17).

For the sensing (sensitivity and selectivity) tests, ${ }^{2} 30 \mu \mathrm{L}$ of the stock solution of COF-LZU8 was diluted with $3 \mathrm{~mL}$ of acetonitrile in a quartz cuvette. COF-LZU8 was readily dispersed in acetonitrile and the obtained suspension was almost transparent. The fluorescence spectra were recorded immediately after an appropriate aliquot of the stock solution of metal ions was added. Each test was repeated at least for three times to get concordant values. All the measurements, unless otherwise noted, were excited at $\lambda_{\mathrm{ex}}=390 \mathrm{~nm}$ and the corresponding emission wavelength was tested from $\lambda_{\mathrm{em}}=410$ to $680 \mathrm{~nm}$. The shape of the emission spectra was not changed upon the addition of the stock solutions of metal ions. The fluorescence titrations were carried 
out via gradually adding the stock solution of $\mathrm{Hg}^{2+}$ in an incremental fashion. Other metal ions (2 equiv.), including $\mathrm{Li}^{+}, \mathrm{Na}^{+}, \mathrm{K}^{+}, \mathrm{Ag}^{+}, \mathrm{Mg}^{2+}, \mathrm{Ca}^{2+}, \mathrm{Ba}^{2+}, \mathrm{Al}^{3+}, \mathrm{Pb}^{2+}, \mathrm{Cu}^{2+}$, $\mathrm{Fe}^{2+}, \mathrm{Fe}^{3+}, \mathrm{Co}^{2+}, \mathrm{Ni}^{2+}, \mathrm{Zn}^{2+}, \mathrm{Sr}^{2+}$, and $\mathrm{Cd}^{2+}$, were used to investigate the selectivity of COF-LZU8 toward the $\mathrm{Hg}^{2+}$ detection. For the recycle tests, $30 \mu \mathrm{L}$ of the stock solution of COF-LZU8 was diluted with $3 \mathrm{~mL}$ of acetonitrile in a quartz cuvette, the fluorescence spectra were measured before and after the stock $\mathrm{Hg}^{2+}$ solution $(33.3$ $\mu \mathrm{mol}$ ) was added. The stock solution of $\mathrm{S}^{2-}$ was further added ${ }^{3}$ to remove $\mathrm{Hg}^{2+}$ from $\mathrm{Hg} / \mathrm{COF}-\mathrm{LZU} 8$, and the recycled COF-LZU8 was reused in the next $\mathrm{Hg}^{2+}$ detection and removal (see Figure S15). The measured fluorescence intensities were used to assess the degree of the recovery. 


\section{Synthetic Procedures}

\section{Synthesis of 2,5-bis(3-(ethylthio)propoxy)terephthalohydrazide (1).}

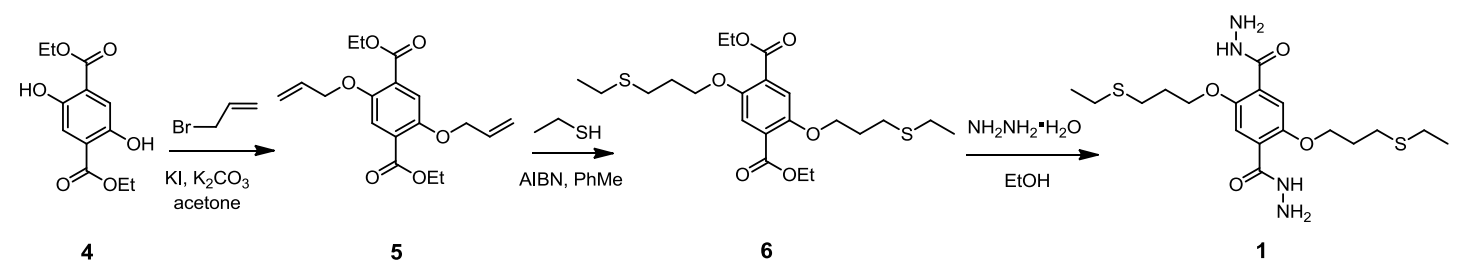

Diethyl 2,5-bis(allyloxy)terephthalate (5). 5 was synthesized according to the reported literature ${ }^{4}$ with a modified procedure. $2.00 \mathrm{~g}(7.8 \mathrm{mmol})$ of diethyl 2,5-dihydroxyterephthalate (4) were dissolved in $150 \mathrm{~mL}$ of acetone, to which $9.0 \mathrm{~g}$ of potassium carbonate and $160 \mathrm{mg}$ of potassium iodide were added. To the mixture, 3.7 $\mathrm{mL}$ of allyl bromide were additionally added and heated to reflux for $40 \mathrm{~h}$. The mixture was hot filtered and the solid residue was washed with acetone. The yellow filtrate was then evaporated to dryness. The obtained residue was suspended in water $(20 \mathrm{~mL})$ and extracted with $3 \times 50 \mathrm{~mL}$ of methylene chloride. The organic extracts were combined, washed with water and brine, and dried over with anhydrous sodium sulfate. The dried solution was then evaporated to obtain the crude product as yellow solid, which was purified by flash chromatographic column (petroleum ether/ethyl acetate: 10/1) to afford 5 (2.47 g, 95\% yield). ${ }^{\mathbf{1}} \mathbf{H}$ NMR (400 MHz, $\left.\mathrm{CDCl}_{3}\right): \delta=7.38$ (s, 2H), 6.10-6.01 (m, 2H), 5.51-5.45 (m, 2H), 5.29-5.27 (m, 2H), 4.60-4.58 (m, 4H), $4.41-4.34(\mathrm{~m}, 4 \mathrm{H}), 1.38(\mathrm{t}, J=8.0 \mathrm{~Hz}, 6 \mathrm{H}) .{ }^{13} \mathrm{C} \mathrm{NMR}\left(100 \mathrm{MHz}, \mathrm{CDCl}_{3}\right): \delta=165.6$, $151.5,132.7,125.0,117.5,117.4,70.6,61.3,14.2$.

Diethyl 2,5-bis(3-(ethylthio)propoxy)terephthalate (6). $0.5 \mathrm{~g}(1.5 \mathrm{mmol})$ of 5 and azodiisobutyronitrile (AIBN) (3.0 mmol, $0.49 \mathrm{~g}$ ) were weighed into a glass ampoule (volume of $c a .20 \mathrm{~mL}$, body length of $18 \mathrm{~cm}$, neck length of $9 \mathrm{~cm}$ ). The ampoule was evacuated on a vacuum line for $10 \mathrm{~min}$ and then injected with argon gas. To the ampoule was added toluene $(1.0 \mathrm{~mL})$ and ethanethiol $(15.0 \mathrm{mmol}, 1.07 \mathrm{~mL})$. Then the ampoule was flash frozen in a liquid nitrogen bath, evacuated to an internal pressure of 0 mbar and flame sealed, reducing the total length by $c a .10 \mathrm{~cm}$. Upon warming to 
room temperature, the ampoule was placed in an oven at $80{ }^{\circ} \mathrm{C}$ for 24 hours. Upon cooling down, the ampoule was broken at the neck, and the reaction mixture was evaporated to obtain the crude product as a yellow solid. The crude product was then purified by flash chromatographic column (ethyl acetate) to afford 6 (0.68 g, $98 \%$ yield). ${ }^{1} \mathbf{H}$ NMR $\left(400 \mathrm{MHz}, \mathrm{CDCl}_{3}\right): \delta=7.36(\mathrm{~s}, 2 \mathrm{H}), 4.38-4.32(\mathrm{~m}, 4 \mathrm{H}), 4.11(\mathrm{t}, J=$ $6.0 \mathrm{~Hz}, 4 \mathrm{H}), 2.74(\mathrm{t}, J=7.2 \mathrm{~Hz}, 4 \mathrm{H}), 2.55-2.50(\mathrm{~m}, 4 \mathrm{H}), 2.10-2.03(\mathrm{~m}, 4 \mathrm{H}), 1.37(\mathrm{t}, J$ $=7.2 \mathrm{~Hz}, 6 \mathrm{H}), 1.24(\mathrm{t}, J=7.2 \mathrm{~Hz}, 6 \mathrm{H}) .{ }^{13} \mathbf{C ~ N M R}\left(100 \mathrm{MHz}, \mathrm{CDCl}_{3}\right): \delta=165.5$, 151.4, 124.5, 116.4, 67.8, 61.0, 29.0, 27.7, 25.7, 14.5, 14.1. ESI-HRMS: calcd. for $\left[\mathrm{C}_{22} \mathrm{H}_{34} \mathrm{O}_{6} \mathrm{~S}_{2}+\mathrm{H}\right]$ 459.1797, found 459.1868 .

2,5-Bis(3-(ethylthio)propoxy)terephthalohydrazide (1). $1.00 \mathrm{~g}$ (2.2 mmol) of 6 was dissolved in $45 \mathrm{~mL}$ of ethanol and $6 \mathrm{~mL}$ of hydrazine hydrate. The mixture was stirred and heated to reflux for $12 \mathrm{~h}$. After cooling, white crystals precipitated, which were isolated by filtration, and washed thoroughly with water and ethanol. The white solid was then dried to obtain the final product of $\mathbf{1}\left(0.76 \mathrm{~g}, 80 \%\right.$ yield). ${ }^{\mathbf{1}} \mathbf{H} \mathbf{~ N M R}$ $\left(400 \mathrm{MHz}, \mathrm{DMSO}-d_{6}\right): \delta=9.23(\mathrm{~s}, 2 \mathrm{H}), 7.32(\mathrm{~s}, 2 \mathrm{H}), 4.57(\mathrm{~s}, 4 \mathrm{H}), 4.11(\mathrm{t}, J=6.0 \mathrm{~Hz}$, 4H), $2.64(\mathrm{t}, J=7.2 \mathrm{~Hz}, 4 \mathrm{H}), 2.54-2.49(\mathrm{~m}, 4 \mathrm{H}), 2.01-1.95(\mathrm{~m}, 4 \mathrm{H}), 1.17(\mathrm{t}, J=7.2$ $\mathrm{Hz}, 6 \mathrm{H}) .{ }^{13} \mathrm{C}$ NMR $\left(100 \mathrm{MHz}, \mathrm{DMSO}-d_{6}\right): \delta=173.8,159.5,135.3,124.6,77.8,38.6$, 37.1, 34.8, 24.6. ESI-HRMS: calcd. for $\left[\mathrm{C}_{18} \mathrm{H}_{30} \mathrm{~N}_{4} \mathrm{O}_{4} \mathrm{~S}_{2}+\mathrm{H}\right]$ 431.1781, found 431.1175 .

\section{Synthesis of 1,3,5-triformylbenzene (2).}

Compound 2 was synthesized according to the reported procedure. ${ }^{5}$ The obtained

${ }^{1} \mathrm{H}$ and ${ }^{13} \mathrm{C}$ NMR spectra of 2 matched well with those reported ${ }^{5}$ previously. 


\section{Synthesis of COF-LZU8.}

2,5-Bis(3-(ethylthio)propoxy)terephthalohydrazide 1 (65 $\mathrm{mg}, 0.15 \mathrm{mmol})$ and 1,3,5-trisformylbenzene $2(16 \mathrm{mg}, 0.10 \mathrm{mmol})$ were weighed into a glass ampoule (volume of $c a .20 \mathrm{~mL}$, body length of $18 \mathrm{~cm}$, neck length of $9 \mathrm{~cm}$ ). To the mixture was added 1,4-dioxane $(1.0 \mathrm{~mL})$, mesitylene $(3.0 \mathrm{~mL})$, and $0.4 \mathrm{~mL}$ of $6.0 \mathrm{~mol} / \mathrm{L}$ aqueous acetic acid. Then the ampoule was flash frozen in a liquid nitrogen bath, evacuated to an internal pressure of 0 mbar and flame sealed, reducing the total length by $c a .10 \mathrm{~cm}$. Upon warming to room temperature, the ampoule was placed in an oven at $120^{\circ} \mathrm{C}$ and left undisturbed for 3 days, yielding a white solid. The ampoule was broken at the neck, and the white solid was isolated by centrifugation and washed with acetone $(3 \times 10 \mathrm{~mL})$ and THF $(3 \times 10 \mathrm{~mL})$, dried at $80{ }^{\circ} \mathrm{C}$ under vacuum for $12 \mathrm{~h}$ to yield COF-LZU8 as a white powder (61 mg, 80\% yield). COF-LZU8 could also be successfully synthesized with high crystallinity under other conditions, such as in 1,4-dioxane [1,4-dioxane/mesitylene/HOAc $\left.\left(\begin{array}{ll}6.0 & \mathrm{M}\end{array}\right)=15 / 30 / 2\right]$ and in ethanol [EtOH/mesitylene/HOAc $(6.0 \mathrm{M})=15 / 30 / 2]$ (see Figure S17). Anal. Cald for $\left(\mathrm{C}_{12} \mathrm{H}_{14} \mathrm{~N}_{2} \mathrm{O}_{2} \mathrm{~S}\right)_{\mathrm{n}}$ : C 57.60; H 5.60; N 11.20, S 12.80. Found: C 56.72; H 5.84; N 10.72, S 12.47. IR (powder, $\mathrm{cm}^{-1}$ ) 3440, 3287, 2962, 2927, 1677, 1621, 1533, 1487, 1442, 1413, 1218, 1079, 1019, 806, 569. The characterization details of COF-LZU8 are presented in the main text and in this Supporting Information.

\section{Synthesis of the model compound 3.}

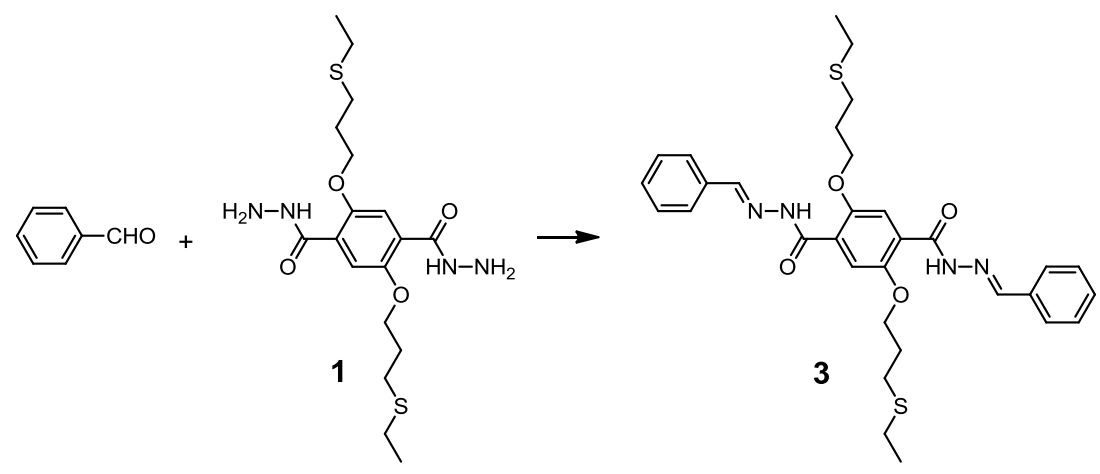

To a solution of 2,5-bis(3-(ethylthio)propoxy)terephthalohydrazide $\mathbf{1}$ (86 mg, 
$0.20 \mathrm{mmol})$ in $\mathrm{MeOH}(10 \mathrm{~mL})$, benzaldehyde (45 $\mu \mathrm{L}, 0.44 \mathrm{mmol})$ was added at room temperature. The mixture was refluxed for $48 \mathrm{~h}$, and white solids were precipitated. The solid was isolated by sucking filtration, washed with $\mathrm{MeOH}$, dried at $80^{\circ} \mathrm{C}$ under vacuum for $12 \mathrm{~h}$ to yield $\mathbf{3}$ as a white powder (103 mg, 85\% yield). ${ }^{\mathbf{1}} \mathbf{H}$ NMR (400 MHz, DMSO- $d_{6}$ ) (major isomer): $\delta=11.56(\mathrm{~s}, 2 \mathrm{H}), 8.30(\mathrm{~s}, 2 \mathrm{H}), 7.73-7.70(\mathrm{~m}, 4 \mathrm{H})$, 7.49-7.27 (m, 6H), 7.37 (s, 2H), 4.18-4.11 (m, 4H), 2.66--2.61 (m, 4H), 2.45-2.39 (m, 4H), 2.01-1.95 (m, 4H), 1.11-1.05 (m, 6H). ${ }^{13} \mathrm{C}$ NMR (100 MHz, DMSO-d $\left.d_{6}\right)$ (major isomer): $\delta=161.9,150.2,147.9,134.7,130.6,129.3,127.5,127.1,115.2,68.5$, 29.3, 27.4, 25.3, 15.1. ESI-HRMS: calcd. for $\left[\mathrm{C}_{32} \mathrm{H}_{38} \mathrm{~N}_{4} \mathrm{O}_{4} \mathrm{~S}_{2}+\mathrm{Na}\right] 629.2334$, found 629.2227. 


\section{FT-IR Spectra}

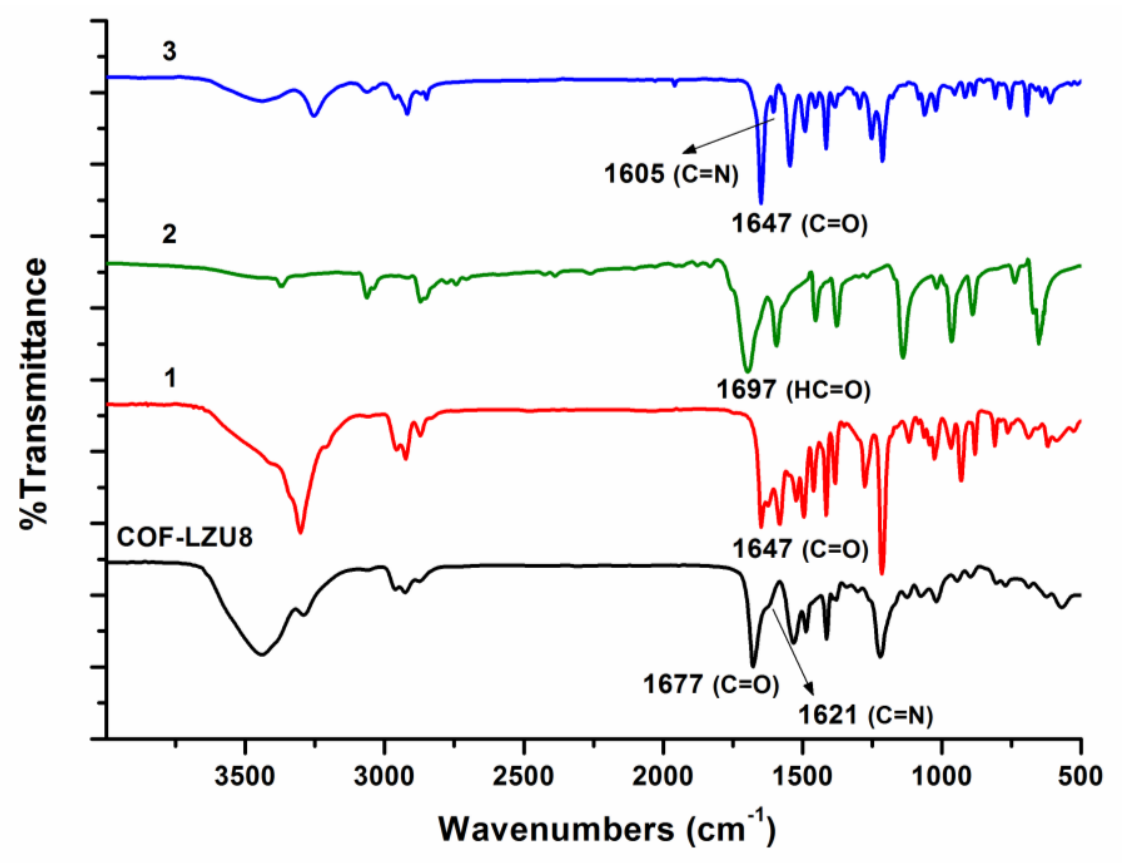

Figure S1. FT-IR spectra of COF-LZU8 (black), the monomer 2,5-bis(3-(ethylthio)propoxy) terephthalohydrazide $\mathbf{1}$ (red), the monomer 1,3,5-triformylbenzene $\mathbf{2}$ (green), and the model compound 3 (blue). In COF-LZU8, the $v_{\mathrm{C}=\mathrm{O}}$ band was observed at $1677 \mathrm{~cm}^{-1}$, which is blue shifted from the corresponding bands $\left(1647 \mathrm{~cm}^{-1}\right)$ of the monomer 1 and the model compound 3. This blue shift can be attributed to the attenuation of the $v_{\mathrm{C}=\mathrm{O}}$ bonds from the adjacent imine bonds, the situation of which has also been observed in COF- $42^{6}$. 


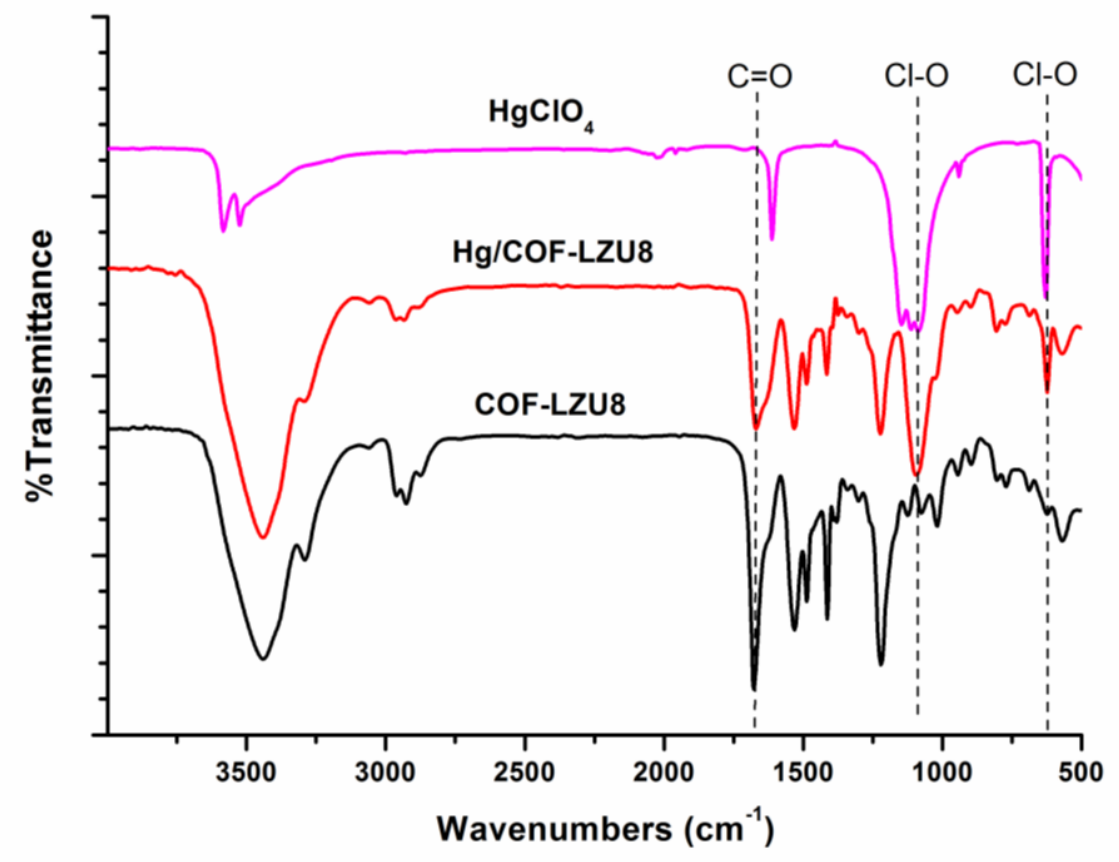

Figure S2. FT-IR spectra of COF-LZU8 (black), Hg/COF-LZU8 (red), and $\mathrm{Hg}\left(\mathrm{ClO}_{4}\right)_{2}$ (purple). The $v_{\mathrm{C}=\mathrm{O}}$ band at $1677 \mathrm{~cm}^{-1}$ was almost unchanged, implying that $\mathrm{Hg}^{2+}$ does not bind to the $-\mathrm{C}=\mathrm{O}$ bonds (instead, to the $\mathrm{S}$ atoms, see the main text) in COF-LZU8. 


\section{E. UV/Vis Absorption Spectra}

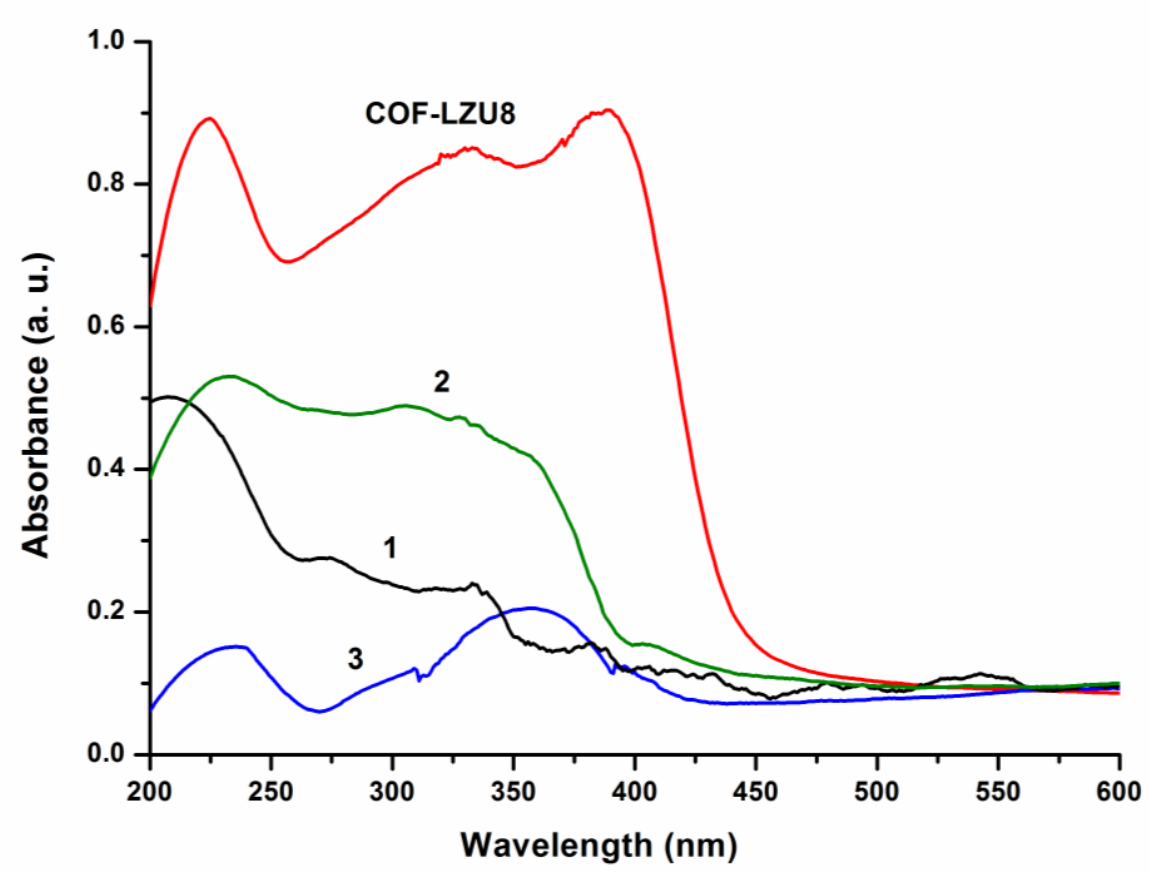

Figure S3. UV/Vis absorption spectra of COF-LZU8 (red), the monomer 2 (green), the monomer 1 (black), and the model compound $\mathbf{3}$ (blue) in the solid state. COF-LZU8 displays a strong UV absorption band at $\sim 390 \mathrm{~nm}$ in the solid state, which is bathochromic from those of its structural monomers $(\mathbf{1}, \mathbf{2}$, and $\mathbf{3})$. This difference is attributed to the existence of the extended $\pi$-conjugation in the COF-LZU8 framework. 


\section{F. Fluorescence Spectra}

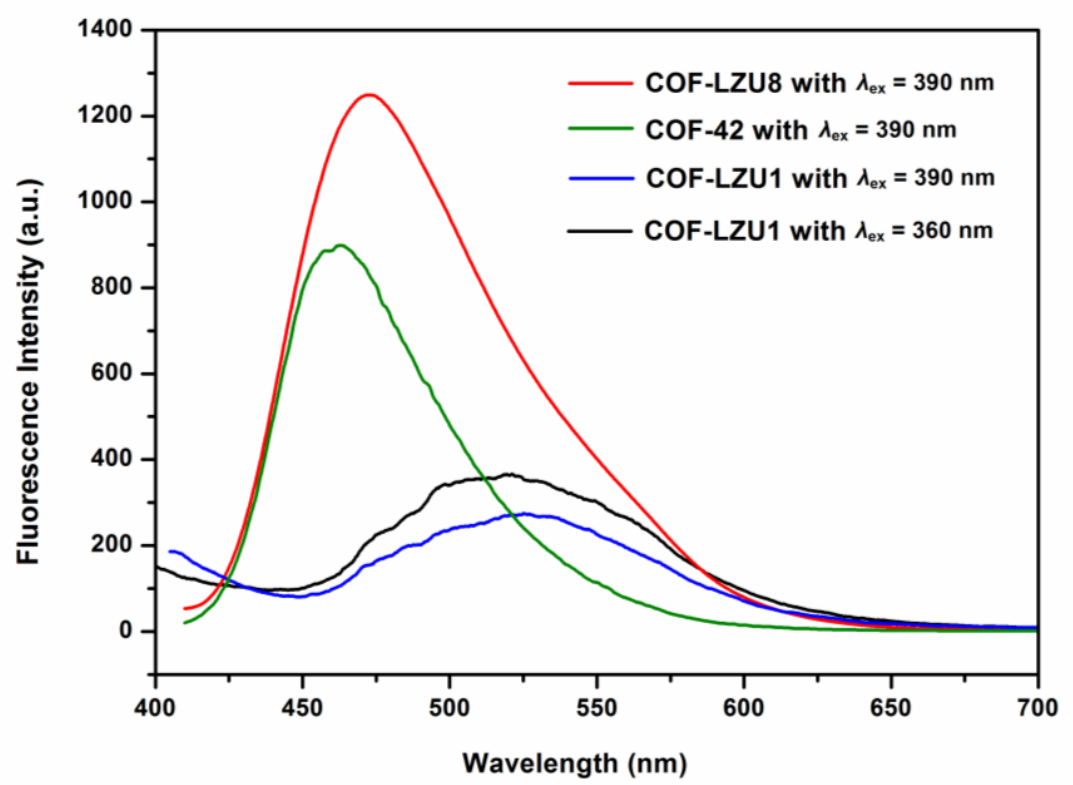

Figure S4. Fluorescence spectra of COF-LZU8 (red), COF-42 (green) and COF-LZU1 (black or blue) in the solid state. In comparison with COF-LZU8, COF-LZU1 shows very weak fluorescence.

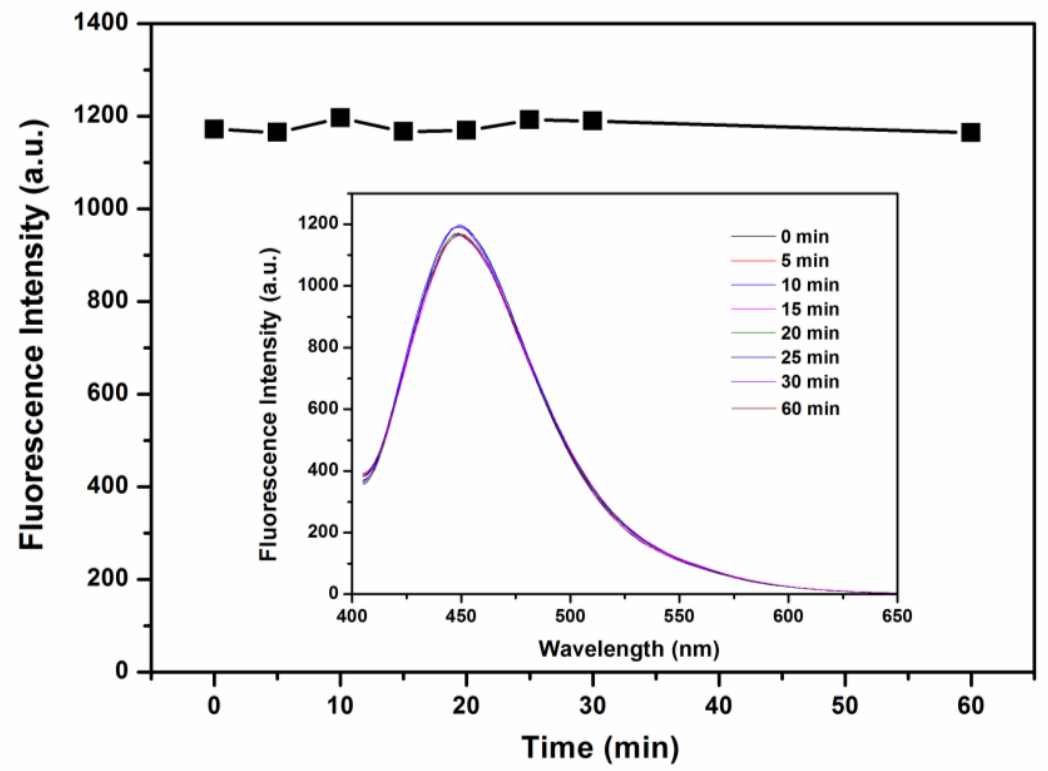

Figure S5. Time-dependent fluorescence intensity of COF-LZU8 (dispersed in acetonitrile) tested within 60 minutes. The unchanged intensity indicates that COF-LZU8 does not show any photo-bleaching, and, the observed decrease in intensities in other cases is indeed induced by the addition of metal ions, such as $\mathrm{Hg}^{2+}$. 


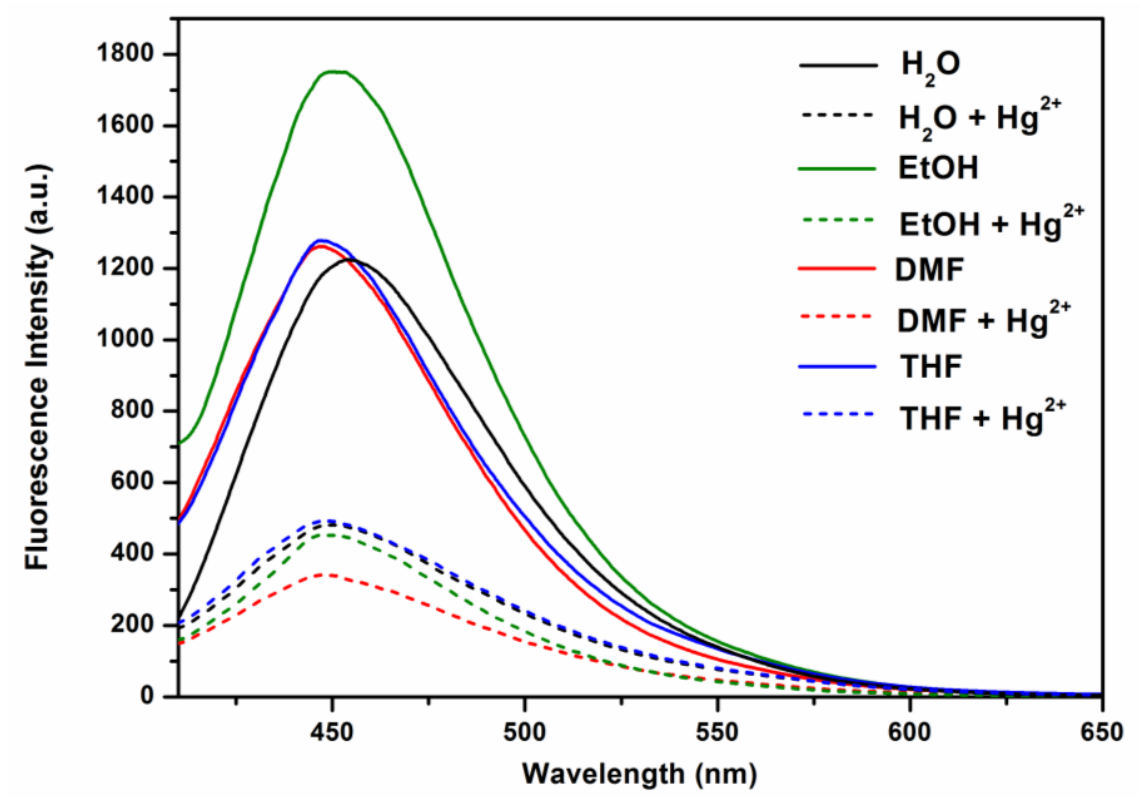

Figure S6. Fluorescence spectra of COF-LZU8 dispersed in $\mathrm{H}_{2} \mathrm{O}$ (black), EtOH (green), DMF (red), and THF (blue) before (solid lines) and after (dashed lines) the addition of $\mathrm{Hg}^{2+}\left(\lambda_{\mathrm{ex}}=390 \mathrm{~nm}\right)$.

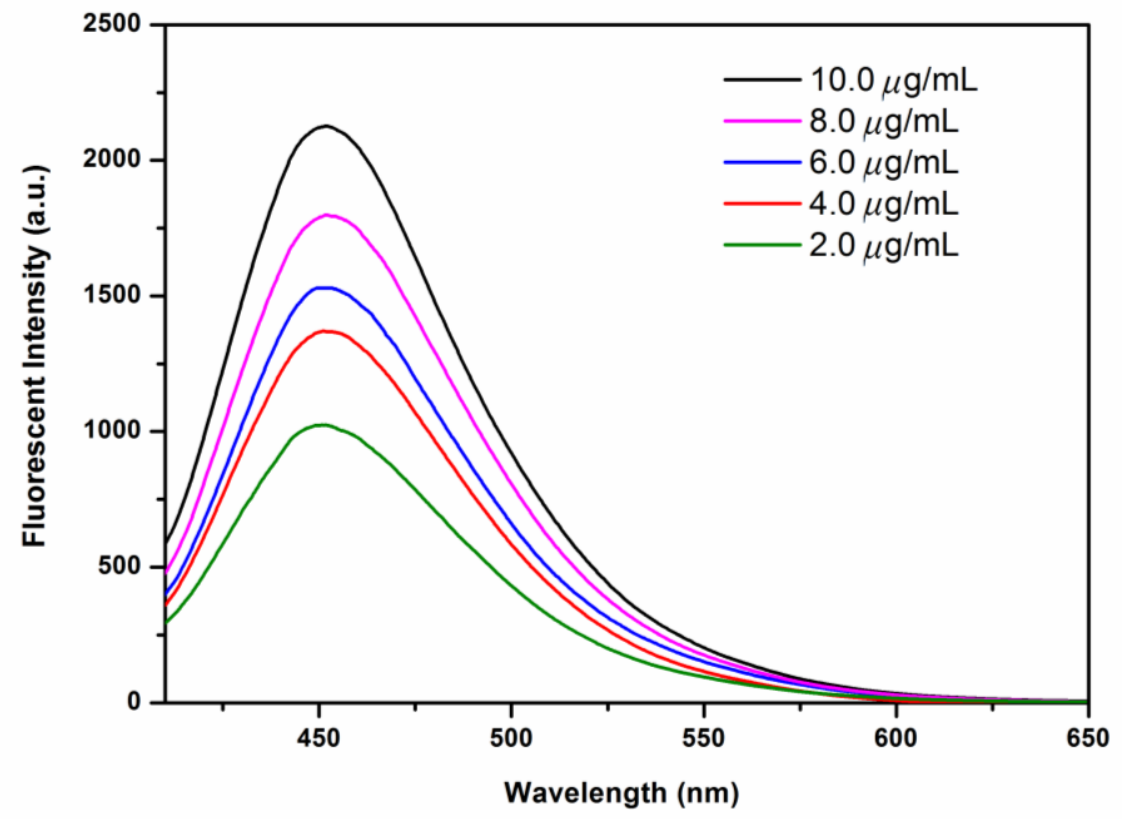

Figure S7. Fluorescence emission intensity against the concentration of COF-LZU8 dispersed in acetonitrile $\left(\lambda_{\mathrm{ex}}=390 \mathrm{~nm}\right)$. 


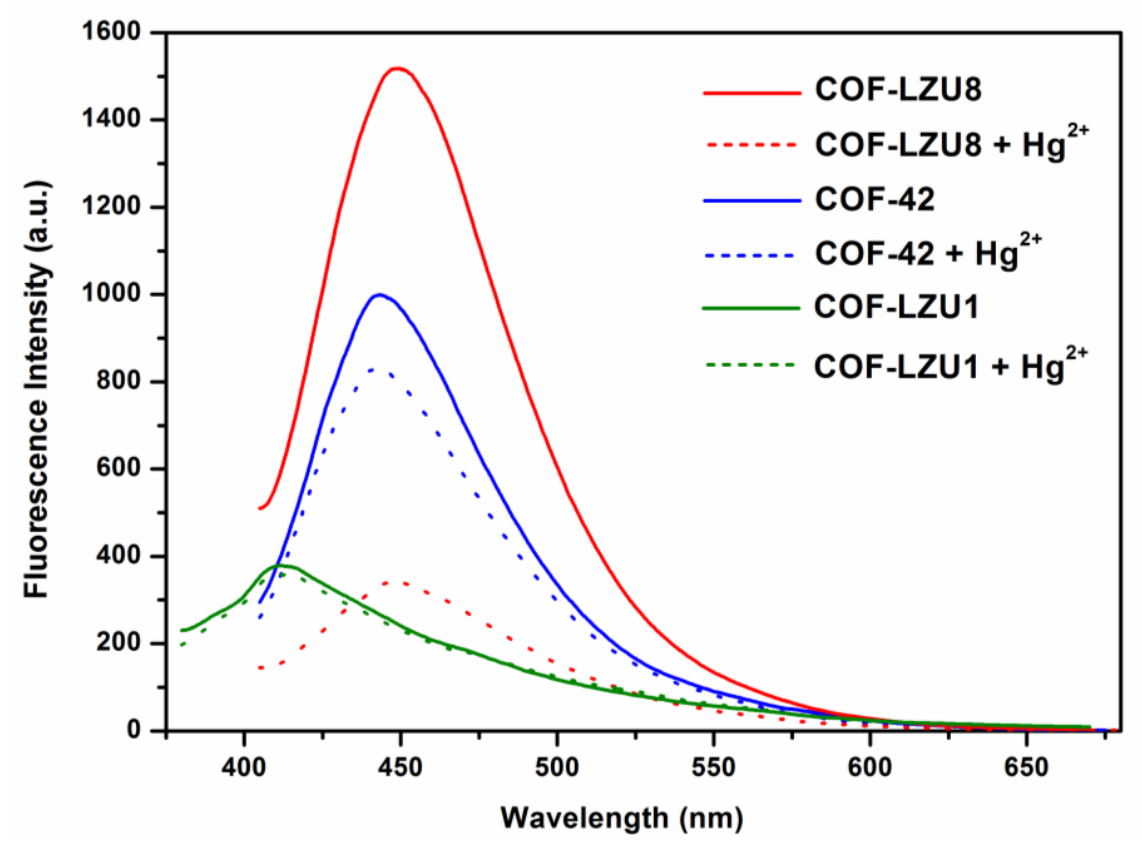

Figure S8. Fluorescence spectra of COF-LZU8 (red), COF-42 (blue), and COF-LZU1 (green) before (solid lines) and after (dashed lines) the addition of $\mathrm{Hg}^{2+}$ (1.0 equiv.) in acetonitrile $\left(\lambda_{\mathrm{ex}}=390 \mathrm{~nm}\right)$. In significant difference from those of COF-LZU1 and COF-42, the effective quenching of the fluorescence in the COF-LZU8 case indicates the unique selectivity of the thioether-based COF-LZU8.

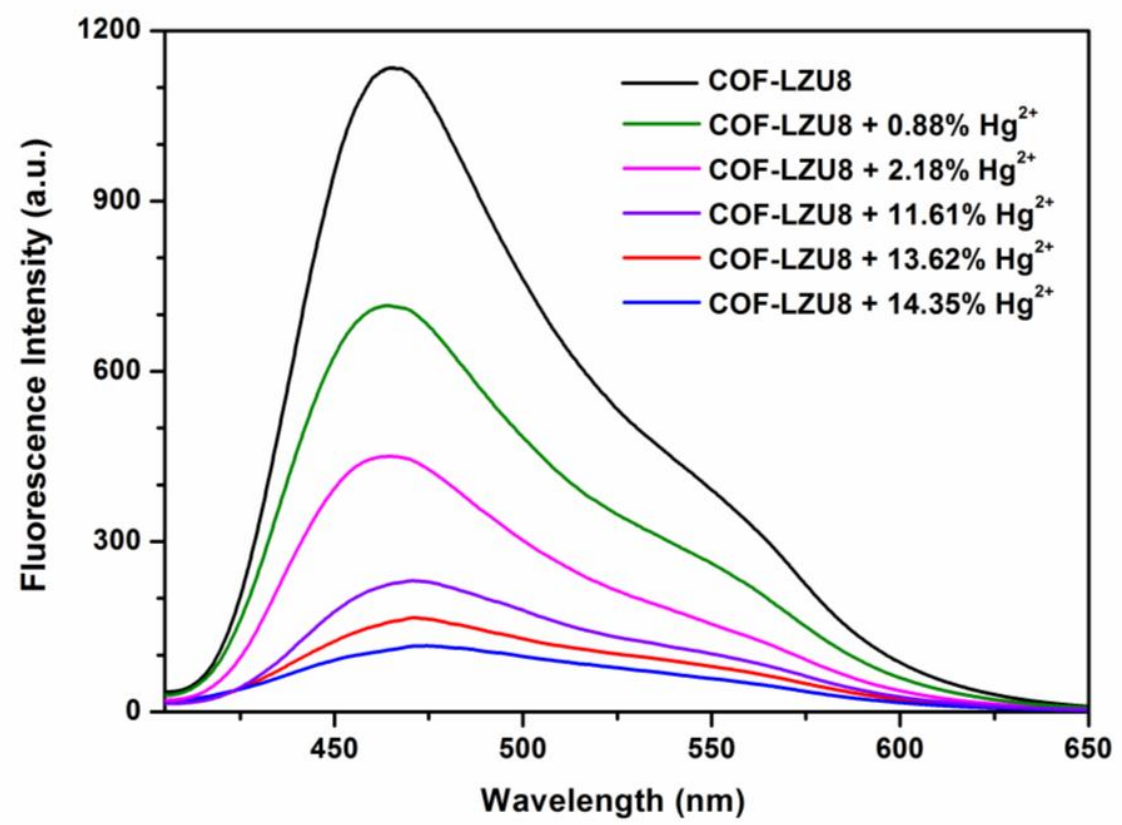

Figure S9. Fluorescence spectra of COF-LZU8 in the solid state $\left(\lambda_{\mathrm{ex}}=390 \mathrm{~nm}\right)$ upon the addition of $\mathrm{Hg}^{2+}$. 


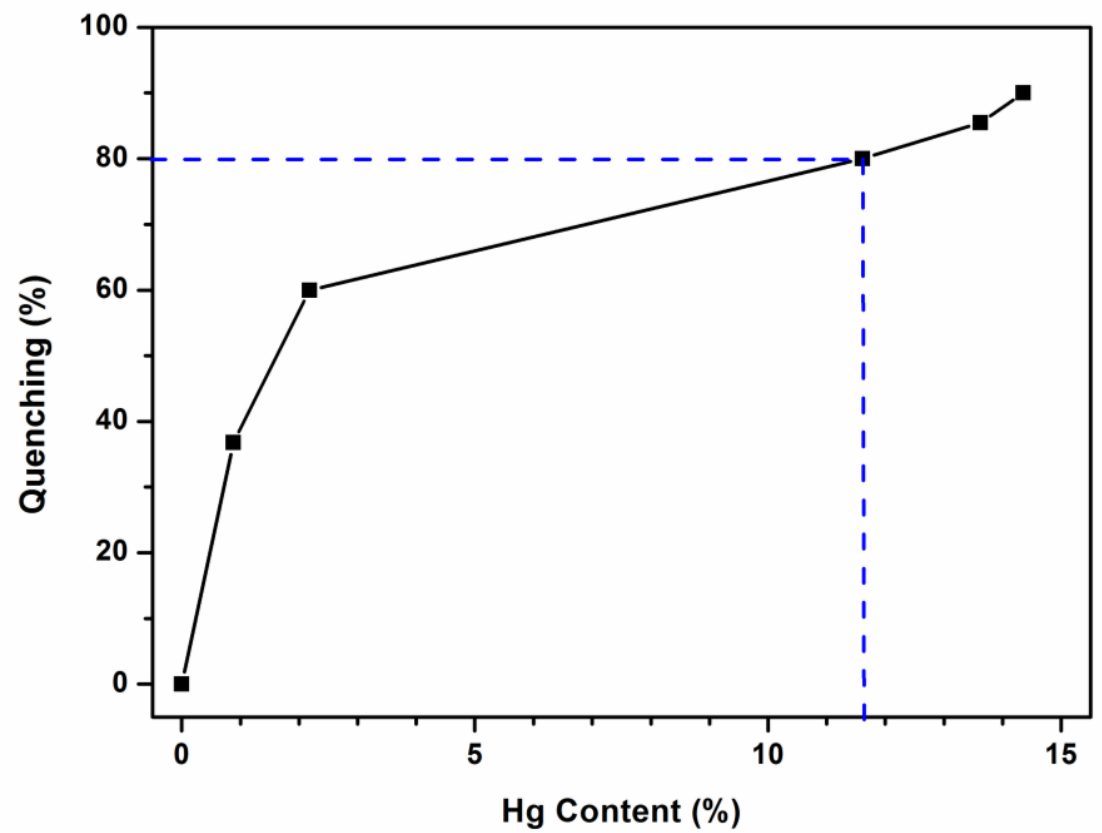

Figure S10. Fluorescence quenching of COF-LZU8 against the $\mathrm{Hg}^{2+}$ content in the solid state $\left(\lambda_{\mathrm{ex}}=390 \mathrm{~nm}\right)$, plotted from the data shown in Figure S9. COF-LZU8 with $11.6 \%$ of $\mathrm{Hg}^{2+}$ content (corresponding to $1.6 \mathrm{Hg}$ atoms per unit cell) resulted in $80 \%$ fluorescence quenching, indicating the amplified fluorescence response of COF-LZU8 in the detection of $\mathrm{Hg}^{2+}$. 


\section{G. The Detection Limit of COF-LZU8 with $\mathrm{Hg}^{2+}$}

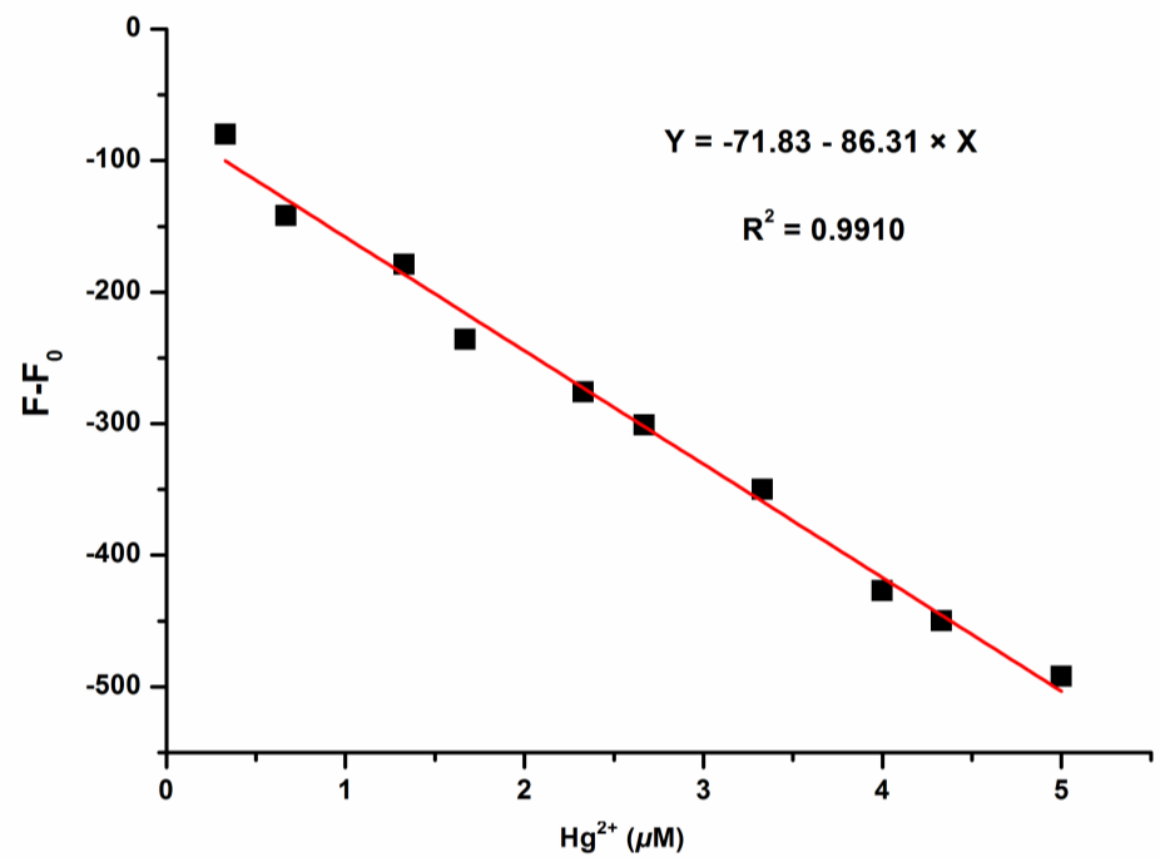

Figure S11. Linear concentration range of $\mathrm{Hg}^{2+}$ for COF-LZU8 in acetonitrile $\left(\lambda_{\mathrm{ex}}=\right.$ $390 \mathrm{~nm})$. The $\mathrm{F}_{0}$ and $\mathrm{F}$ represent the fluorescence emission intensities of COF-LZU8 in the absence and in the presence of $\mathrm{Hg}^{2+}$, respectively. The corresponding limit of detection (LOD) was determined as $25.0 \mathrm{ppb}$ using the equation LOD $=3 \times$ S.D. $/ \mathrm{k}{ }^{7}$ where $\mathrm{k}$ represents the slope of the curve equation, and S.D. is the standard deviation for $\mathrm{F}_{0}$ (the fluorescence intensity of COF-LZU8 in the absence of $\mathrm{Hg}^{2+}$ ). 


\section{H. Structural Modeling and Powder X-Ray Diffraction Analysis}

Molecular modeling of COF-LZU8 was generated with the Materials Studio (ver. 6.0) suite of programs. The initial lattice was created by starting with the space group $P 6 / m$; the parameters of $a=b=30.055 \AA$ and $c=3.700 \AA$ were determined by the MS Reflex Plus module. The proposed structure of COF-LZU8 is similar to that of $\mathrm{COF}-42^{6}$, while the edge of the hexagonal ring was substituted by $\left(N^{1} E\right.$, $N^{4} E$ )- $N^{1}, N^{4}$-dibenzylidene-2,5-bis(3-(ethylthio)propoxy)terephthalohydrazide, the geometry of which was initially optimized with $\mathrm{MS} \mathrm{DMol}^{3}$ module.

Firstly, we degraded the symmetry of the lattice to $P 1$, inserted the optimized monomer in the empty cell, omitted the redundant atoms, and promoted the symmetry to $P 3$, producing the crude structure of COF-LZU8. Then the lattice model was geometry-optimized using the MS Forcite molecular dynamics module (universal force fields, Ewald summations) to obtain the optimized lattice parameters of $a=b=$ $29.131 \AA$ and $c=3.703 \AA$. The optimized structure of COF-LZU8 shows a contorted arrangement, similar to the cyclotricatechylene (CTC) and cyclotriveratrylene (CTV) containing COFs. ${ }^{8}$ Finally, Pawley refinement was applied to define the lattice parameters, producing the refined PXRD profile with the lattice parameters of $a=b=$ $29.030( \pm 0.466) \AA$ and $c=3.667( \pm 0.057) \AA$. The $w R \mathrm{p}$ and $R \mathrm{p}$ values converged to $8.20 \%$ and $6.80 \%$, respectively (line broadening from the crystallite size and lattice strain were both concerned). A staggered arrangement for COF-LZU8 was constructed wherein the alternating stacked units were offset by $a / 2$ and $b / 2$ (see Figure S13). 
Table S1. Fractional atomic coordinates for the unit cell of COF-LZU8.

\begin{tabular}{|c|c|c|c|}
\hline \multicolumn{4}{|c|}{$\begin{array}{l}\text { COF-LZU8: Space group symmetry P3 } \\
a=b=29.131 \AA \quad c=3.703 \AA \\
\text { alpha }=\text { beta }=90^{\circ} \quad \text { gamma }=120^{\circ}\end{array}$} \\
\hline Atom & $x(\AA)$ & $y(\AA)$ & $z(\AA)$ \\
\hline $\mathrm{C} 1$ & 0.28258 & -0.85350 & 0.54982 \\
\hline $\mathrm{C} 2$ & 0.29629 & -0.89304 & 0.49543 \\
\hline $\mathrm{C} 3$ & 0.34700 & -0.87987 & 0.61474 \\
\hline $\mathrm{C} 4$ & 0.38562 & -0.82689 & 0.70955 \\
\hline $\mathrm{C} 5$ & 0.37106 & -0.78793 & 0.77136 \\
\hline C6 & 0.31849 & -0.80468 & 0.71878 \\
\hline O7 & 0.40949 & -0.73200 & 0.77293 \\
\hline $\mathrm{C} 8$ & 0.40048 & -0.69050 & 0.90239 \\
\hline C9 & 0.44787 & -0.63415 & 0.79601 \\
\hline $\mathrm{C} 10$ & 0.42953 & -0.59249 & 0.80231 \\
\hline S11 & 0.48107 & -0.52571 & 0.65301 \\
\hline $\mathrm{C} 12$ & 0.43672 & -0.50026 & 0.51523 \\
\hline $\mathrm{C} 13$ & 0.46882 & -0.44442 & 0.35032 \\
\hline $\mathrm{O} 14$ & 0.26179 & -0.94228 & 0.31208 \\
\hline $\mathrm{C} 15$ & 0.27468 & -0.98409 & 0.32481 \\
\hline $\mathrm{C} 16$ & 0.22538 & -1.03723 & 0.22463 \\
\hline $\mathrm{C} 17$ & 0.23717 & -1.08276 & 0.16038 \\
\hline S18 & 0.17755 & -1.14649 & 0.23756 \\
\hline $\mathrm{C} 19$ & 0.20747 & -1.18832 & 0.19797 \\
\hline $\mathrm{C} 20$ & 0.16719 & -1.24473 & 0.32397 \\
\hline $\mathrm{C} 21$ & 0.44010 & -0.81276 & 0.63322 \\
\hline $\mathrm{N} 22$ & 0.48127 & -0.76189 & 0.63959 \\
\hline $\mathrm{O} 23$ & 0.44729 & -0.84621 & 0.48489 \\
\hline $\mathrm{N} 24$ & 0.52597 & -0.74654 & 0.42527 \\
\hline $\mathrm{C} 25$ & 0.56272 & -0.69743 & 0.40008 \\
\hline $\mathrm{C} 26$ & 0.61182 & -0.68327 & 0.21245 \\
\hline $\mathrm{C} 27$ & 0.62714 & -0.72110 & 0.18264 \\
\hline $\mathrm{C} 28$ & 0.23047 & -0.86077 & 0.47306 \\
\hline $\mathrm{O} 29$ & 0.22310 & -0.82422 & 0.55073 \\
\hline $\mathrm{N} 30$ & 0.18724 & -0.90889 & 0.40267 \\
\hline $\mathrm{N} 31$ & 0.13907 & -0.92155 & 0.56076 \\
\hline $\mathrm{C} 32$ & 0.10550 & -0.96997 & 0.64745 \\
\hline $\mathrm{C} 33$ & 0.05481 & -0.98319 & 0.80567 \\
\hline $\mathrm{C} 34$ & 0.03920 & -0.94545 & 0.83466 \\
\hline $\mathrm{H} 35$ & 0.35942 & -0.90902 & 0.58345 \\
\hline H36 & 0.30654 & -0.77709 & 0.79477 \\
\hline
\end{tabular}




\begin{tabular}{|c|c|c|c|}
\hline H37 & 0.39702 & -0.69394 & 1.19732 \\
\hline H38 & 0.36260 & -0.69444 & 0.79923 \\
\hline H39 & 0.46307 & -0.63525 & 0.52321 \\
\hline H40 & 0.48466 & -0.61987 & 0.96914 \\
\hline H41 & 0.41844 & -0.58969 & 1.08152 \\
\hline H42 & 0.39212 & -0.60583 & 0.64888 \\
\hline H43 & 0.41033 & -0.50173 & 0.73890 \\
\hline H44 & 0.40884 & -0.52642 & 0.30463 \\
\hline H45 & 0.49865 & -0.44515 & 0.16613 \\
\hline H46 & 0.48933 & -0.41481 & 0.56493 \\
\hline H47 & 0.44169 & -0.43480 & 0.19750 \\
\hline H48 & 0.28865 & -0.98784 & 0.59514 \\
\hline H49 & 0.30844 & -0.97441 & 0.14188 \\
\hline H50 & 0.20769 & -1.03122 & -0.01965 \\
\hline H51 & 0.19343 & -1.04885 & 0.42988 \\
\hline H52 & 0.26986 & -1.08018 & 0.33012 \\
\hline H53 & 0.24945 & -1.08248 & -0.12108 \\
\hline H54 & 0.24557 & -1.17160 & 0.35262 \\
\hline H55 & 0.21863 & -1.18916 & -0.08528 \\
\hline H56 & 0.18887 & -1.26295 & 0.45605 \\
\hline H57 & 0.13865 & -1.27093 & 0.10945 \\
\hline H58 & 0.13970 & -1.24374 & 0.53588 \\
\hline H59 & 0.48077 & -0.73456 & 0.81520 \\
\hline H60 & 0.55983 & -0.66701 & 0.54578 \\
\hline H61 & 0.59765 & -0.76238 & 0.21115 \\
\hline H62 & 0.19066 & -0.93864 & 0.27340 \\
\hline H63 & 0.11416 & -1.00167 & 0.59811 \\
\hline H64 & 0.06755 & -0.90363 & 0.82305 \\
\hline & & & \\
\hline
\end{tabular}




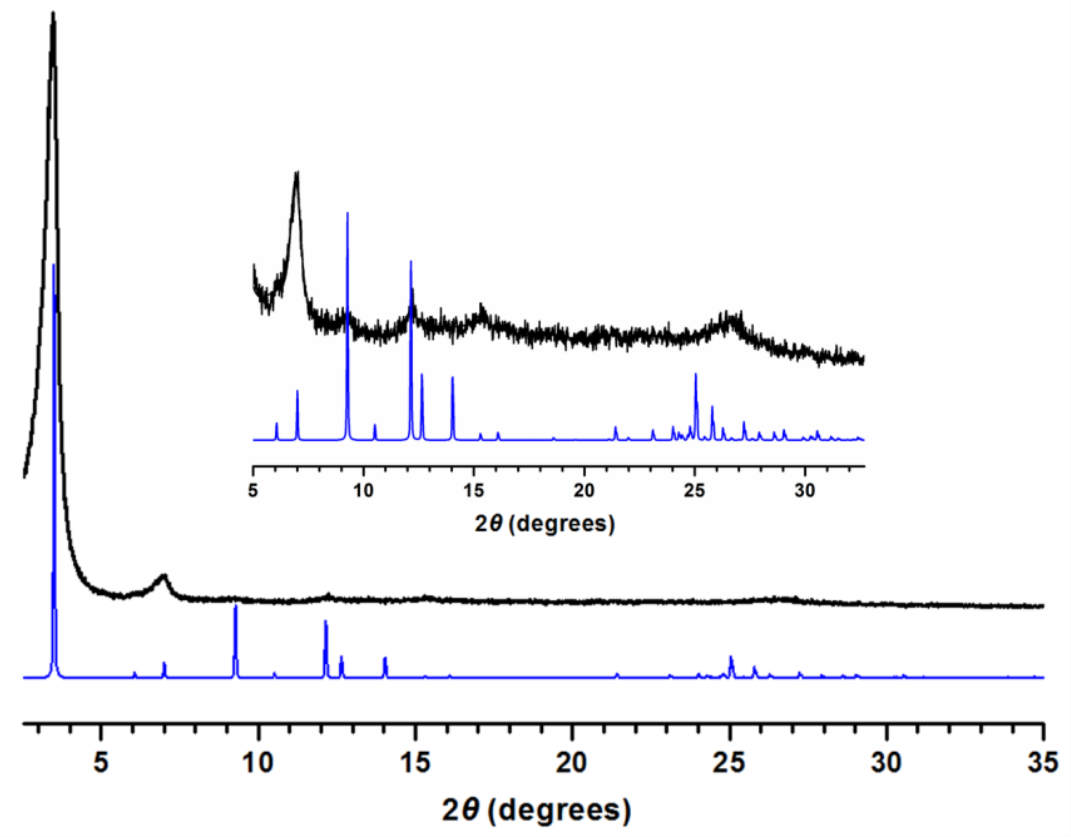

Figure S12. PXRD patterns of COF-LZU8: observed (black) and calculated (blue) with the eclipsed stacking structure. (Inset) Expansion of observed (black) and calculated (blue) PXRD profiles.

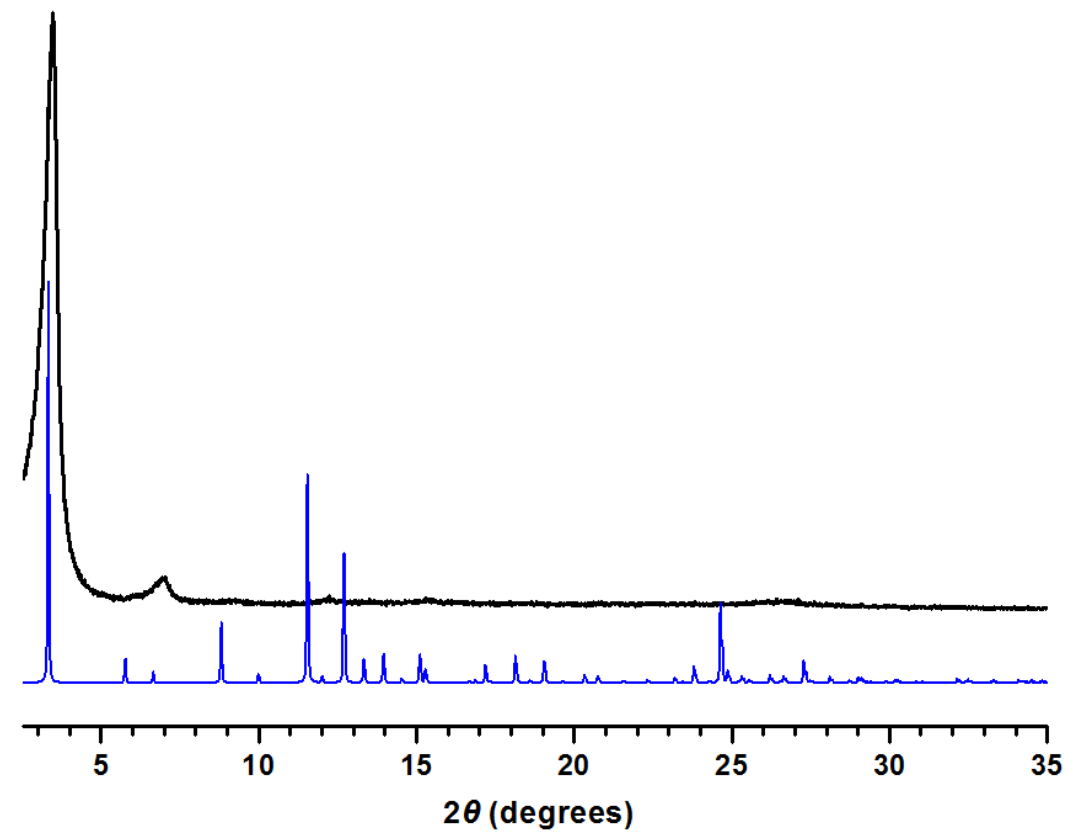

Figure S13. PXRD patterns of COF-LZU8: observed (black) and calculated (blue) with the staggered stacking structure. 


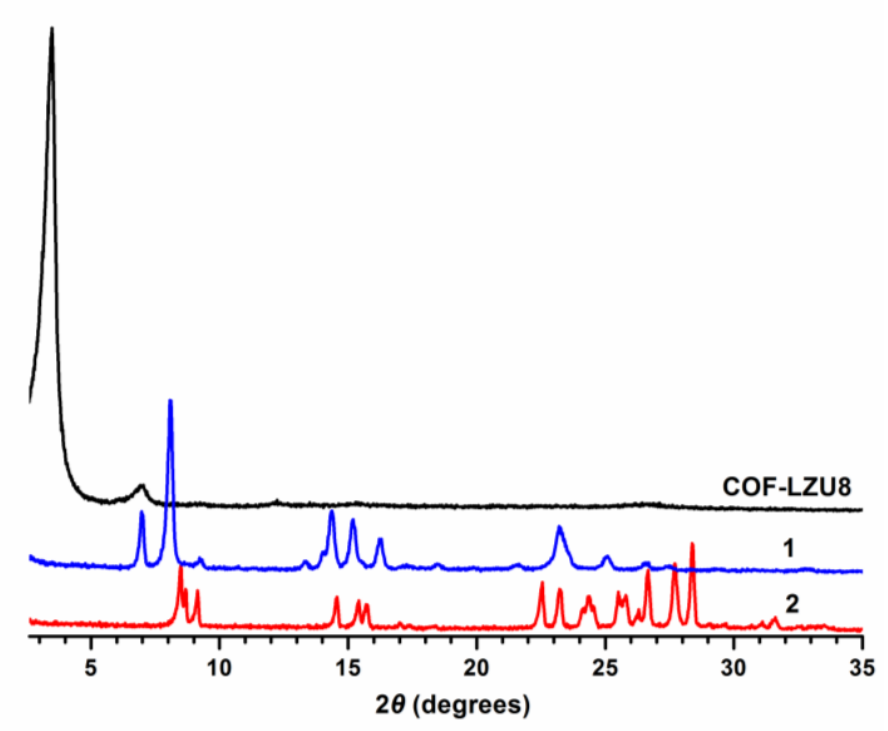

Figure S14. PXRD patterns of COF-LZU8 (black), the monomer 1 (blue), and the monomer 2 (red).

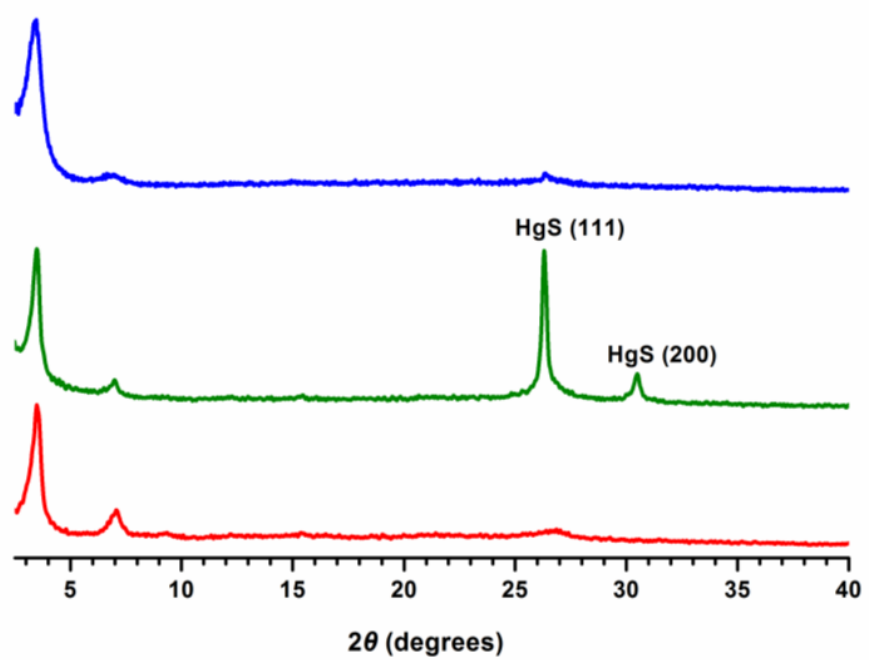

Figure S15. PXRD patterns of COF-LZU8 (red) and the recycled COF-LZU8 after the treatment with 1.0 equiv. (green) and 10.0 equiv. (blue) of aqueous $\mathrm{Na}_{2} \mathrm{~S}$ solution. It can be seen that the COF-LZU8 crystalline structure was well preserved after the recycle use. Two additional peaks, corresponding to the (111) and (200) facets of $\mathrm{HgS}$, appeared (green) in the PXRD patterns of the recycled COF-LZU8 after the treatment with 1.0 equiv. of aqueous $\mathrm{Na}_{2} \mathrm{~S}$ solution, indicating the successful deposition of $\mathrm{Hg}^{2+}$ via the addition of $\mathrm{Na}_{2} \mathrm{~S}$. Upon further addition of aqueous $\mathrm{Na}_{2} \mathrm{~S}$ solution (10.0 equiv.), the $\mathrm{HgS}$ peaks disappeared (blue): the insoluble $\mathrm{HgS}$ was easily removed via the formation of soluble $\left[\mathrm{HgS}_{2}\right]^{2-}$ complex upon the addition of excess $\mathrm{Na}_{2} \mathrm{~S}$ solution. ${ }^{3 \mathrm{c}, 3 \mathrm{~d}}$ 


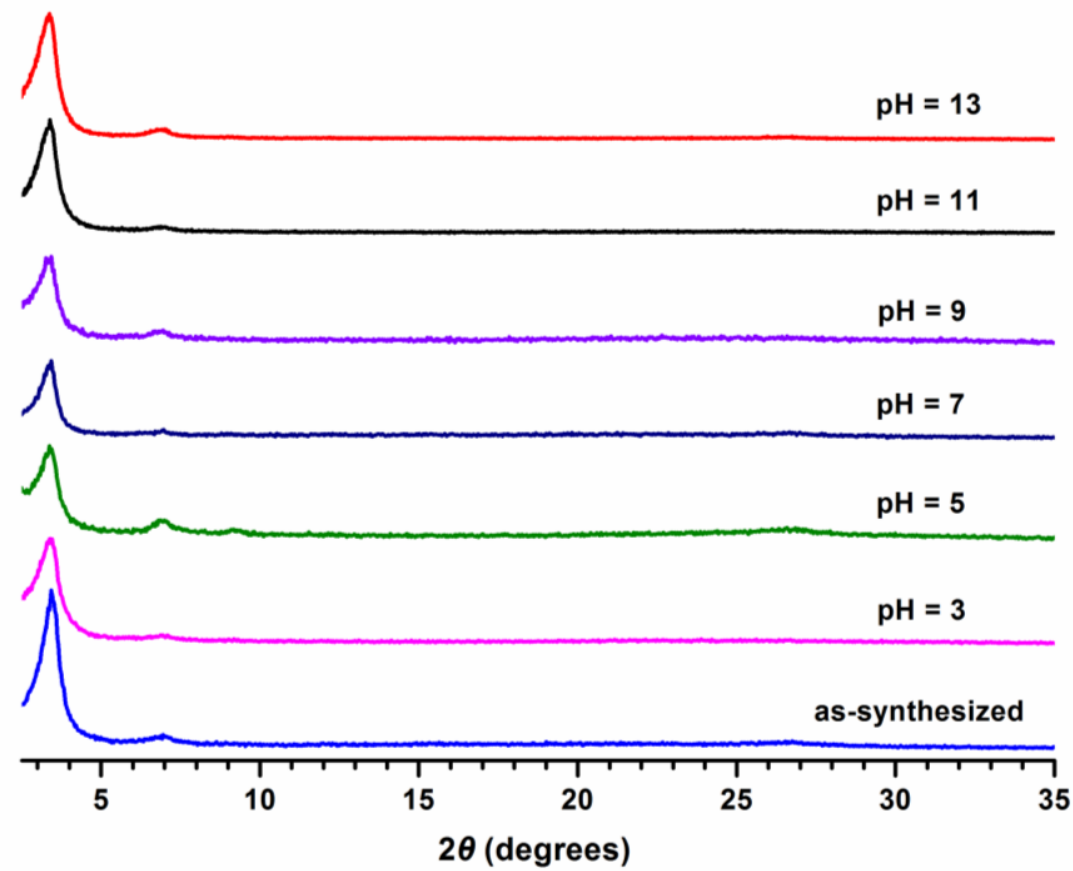

Figure S16. PXRD patterns of COF-LZU8 before and after the treatment in aqueous solutions with different $\mathrm{pH}$ values from 3 to 13. The PXRD patterns of COF-LZU8 are preserved in these conditions, indicating its remarkable stability.

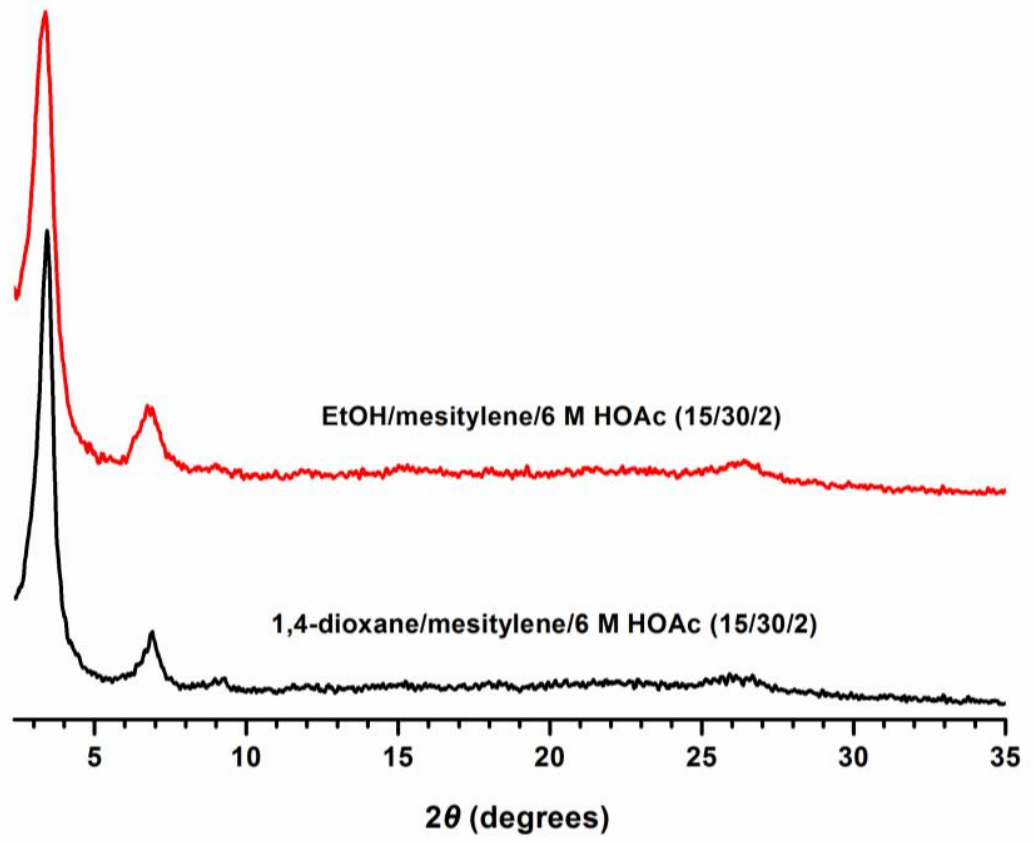

Figure S17. PXRD patterns of COF-LZU8 synthesized under other conditions, such as in 1,4-dioxane/mesitylene/6.0 M HOAc (15/30/2) (black) or in EtOH/mesitylene/ 6.0 M HOAc (15/30/2) (red). 


\section{I. $\mathbf{N}_{2}$ Adsorption-Desorption Analysis}

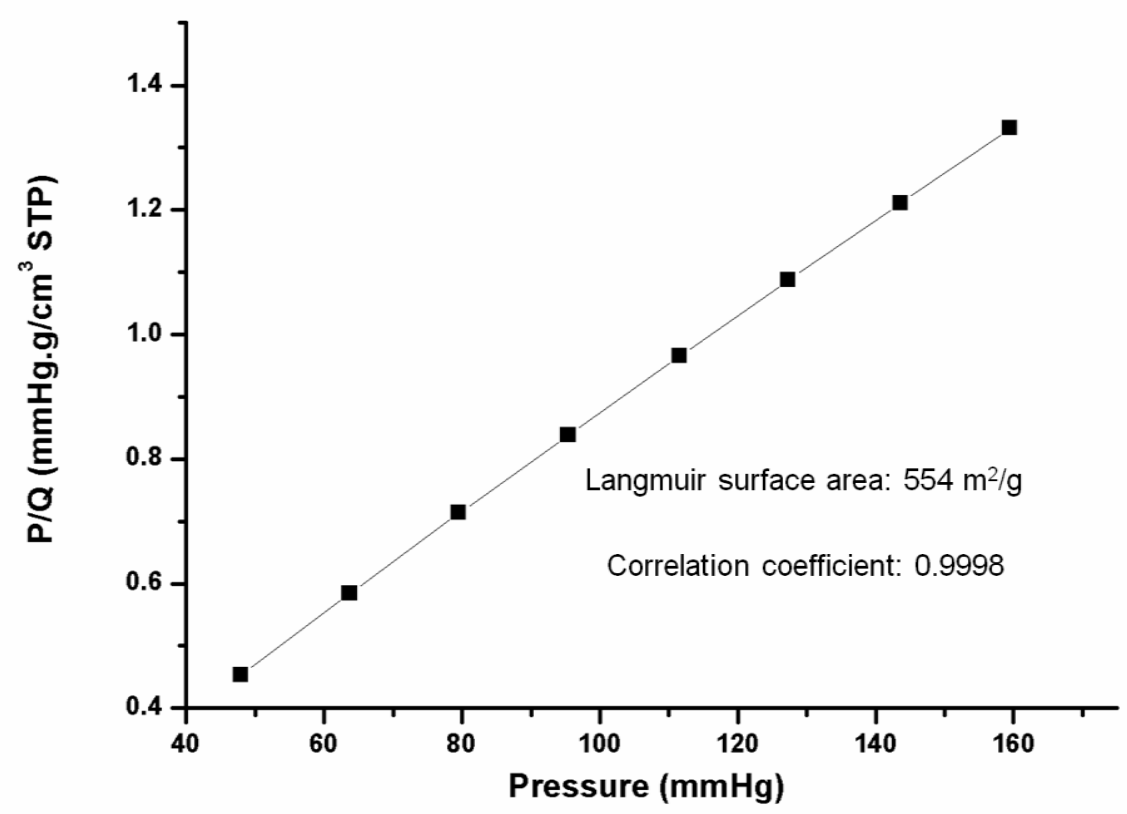

Figure S18. Langmuir surface area plot for COF-LZU8 calculated from the isotherm.

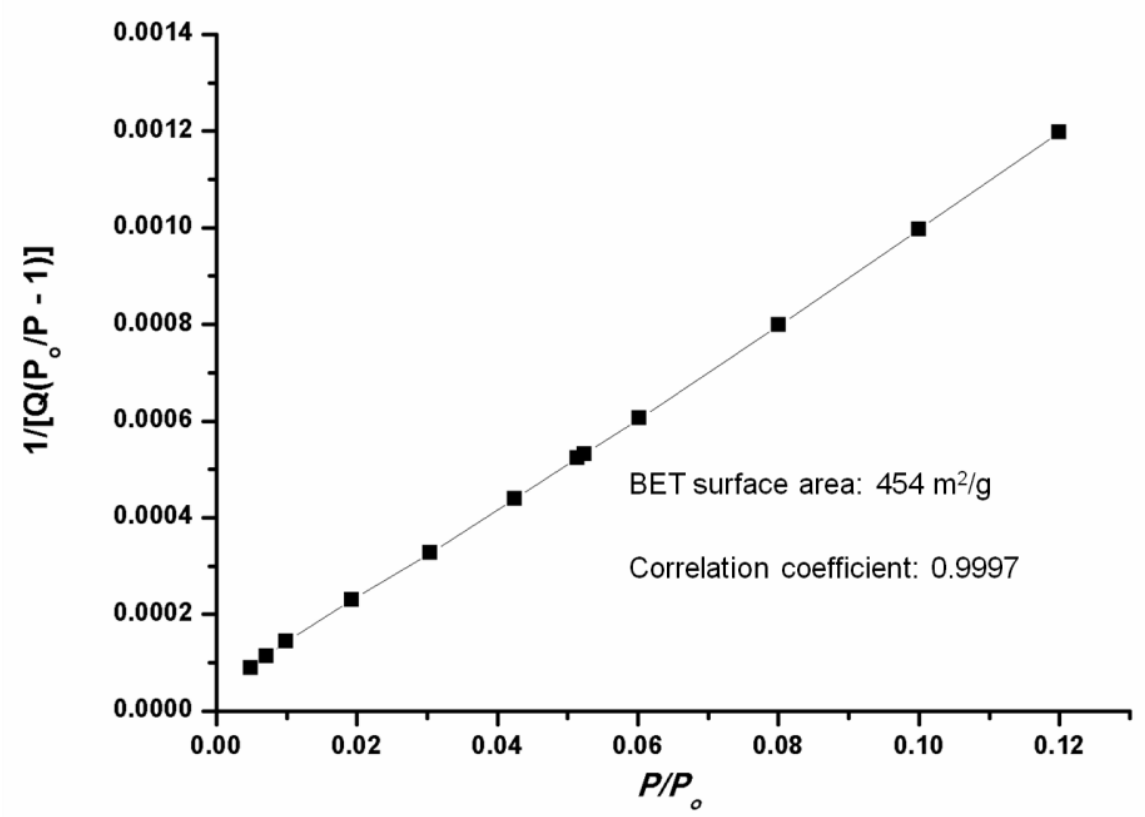

Figure S19. BET surface area plot for COF-LZU8 calculated from the isotherm. 


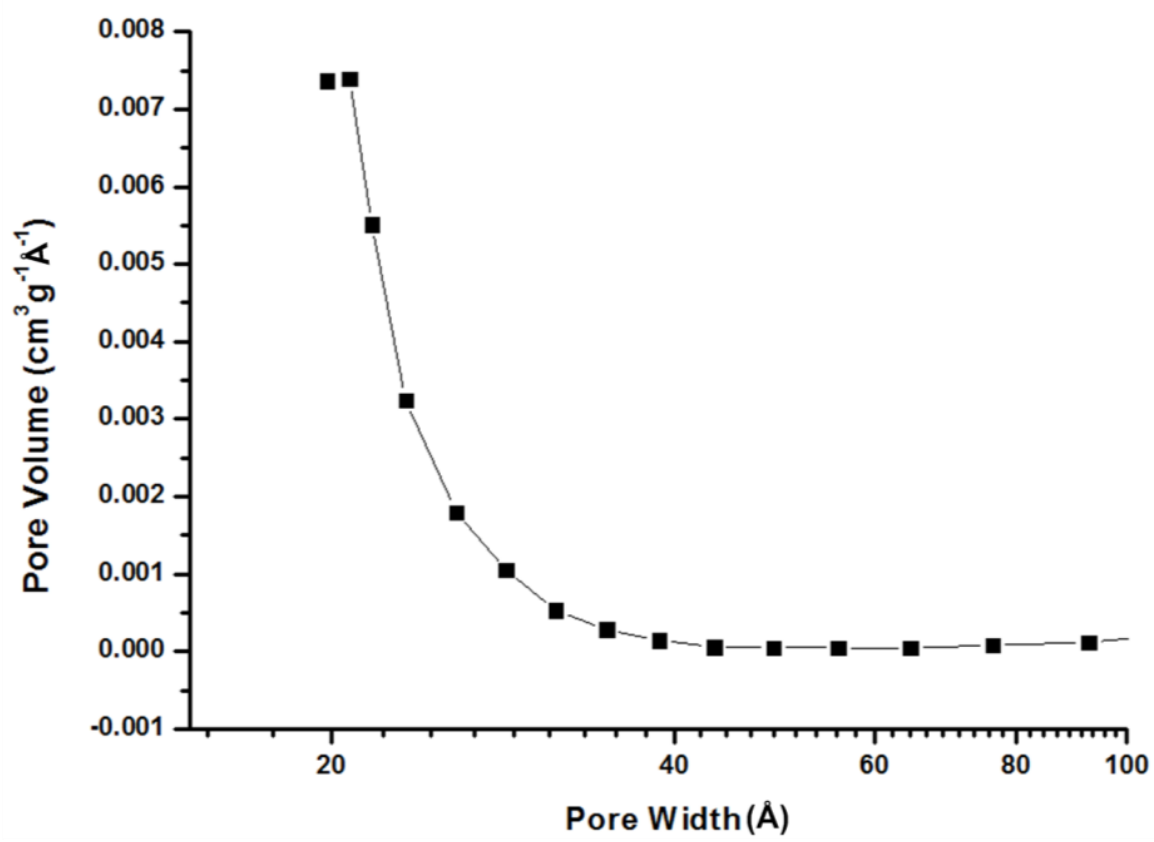

Figure S20. Pore size distribution of COF-LZU8 calculated by the BJH method based on the adsorption isothermal. 
J. Thermogravimetric Analysis

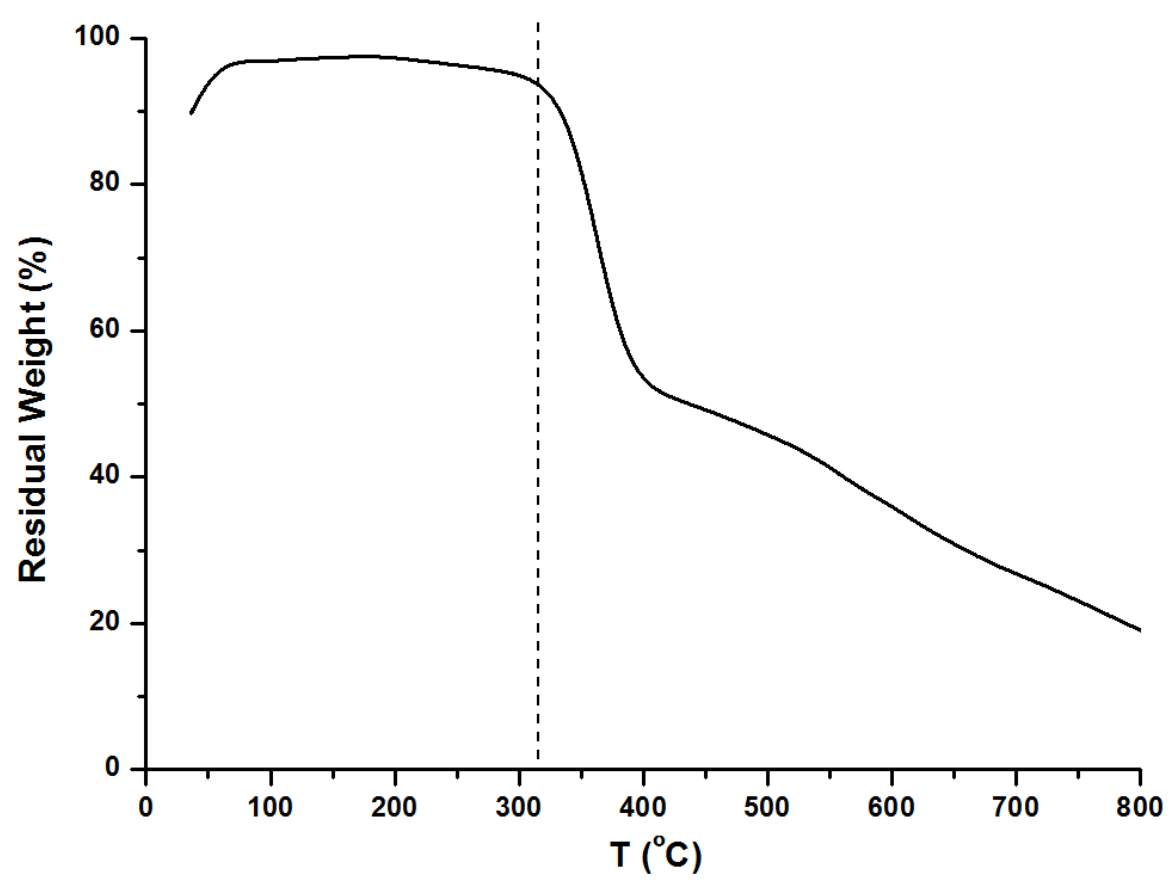

Figure S21. TGA data for COF-LZU8. 


\section{K. Scanning Electron Micrographs}
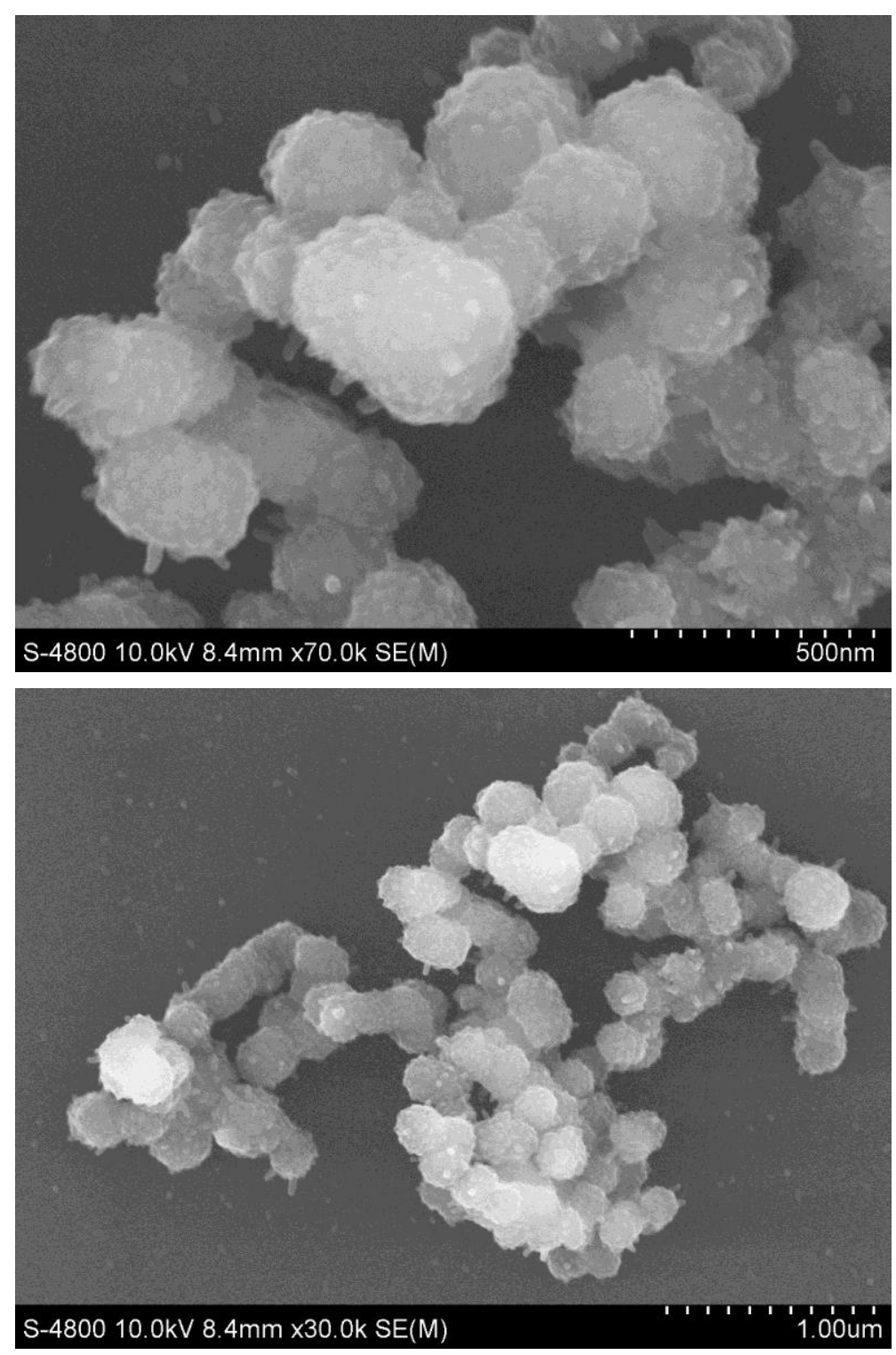

Figure S22. SEM images of COF-LZU8. 


\section{Liquid NMR Spectra}

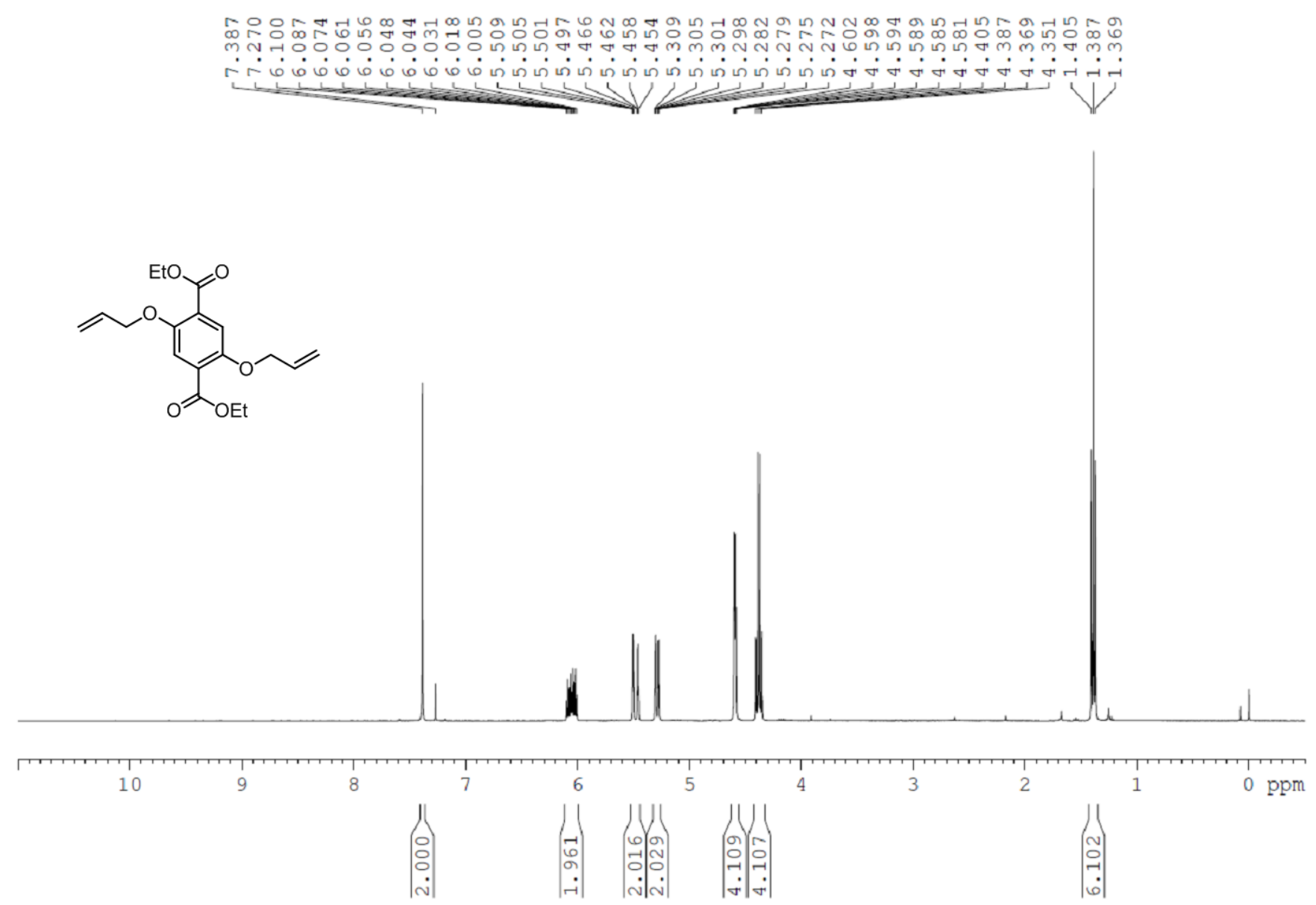



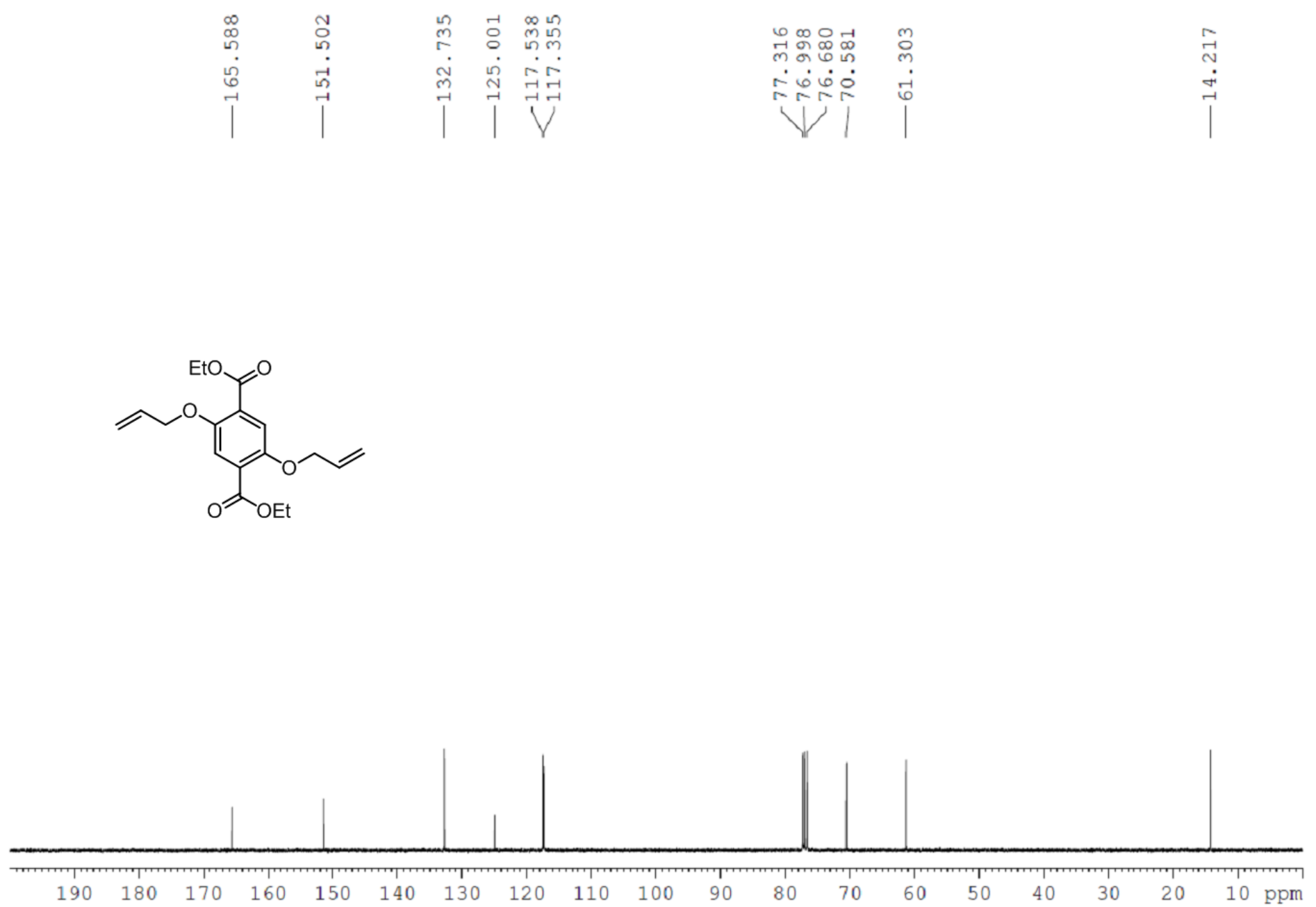

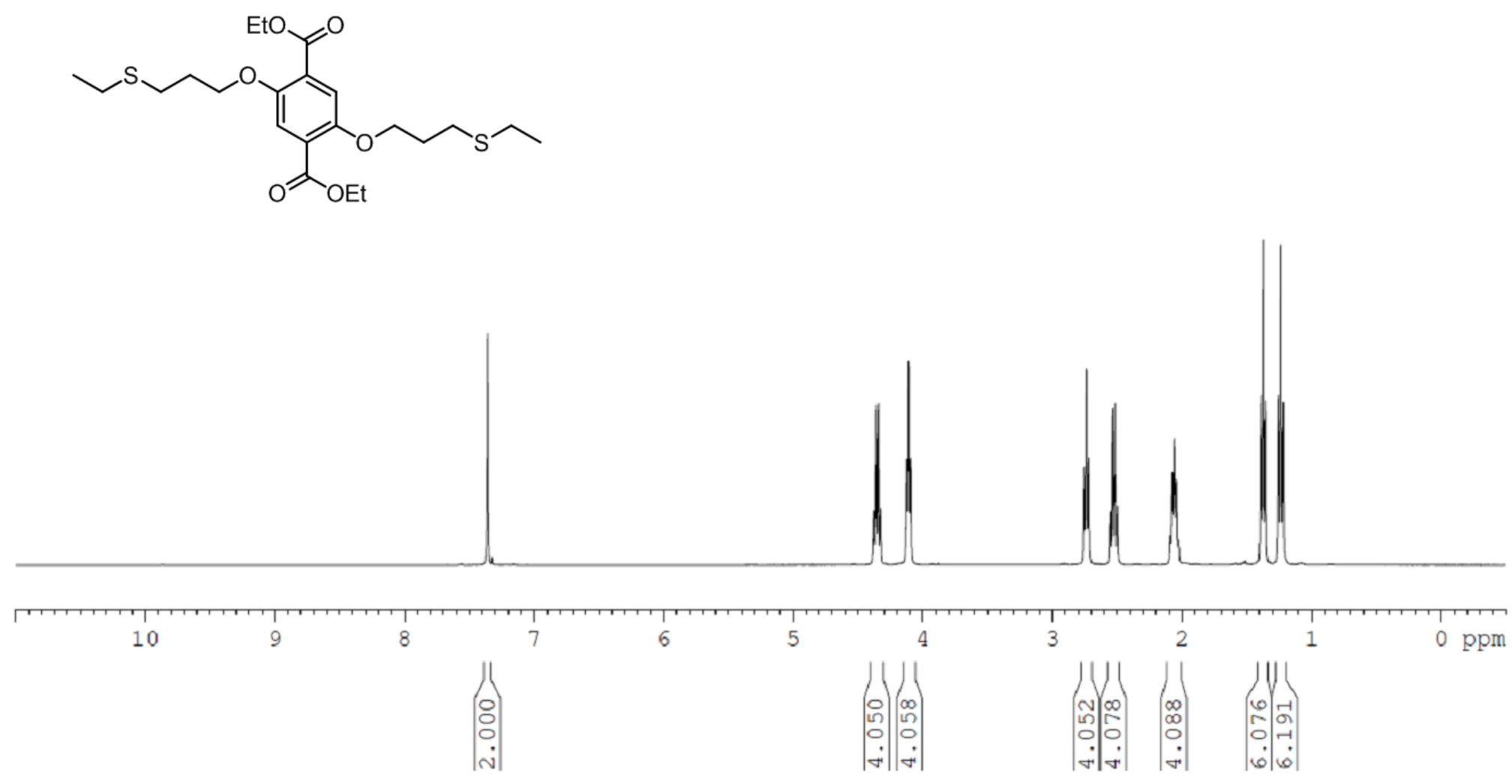

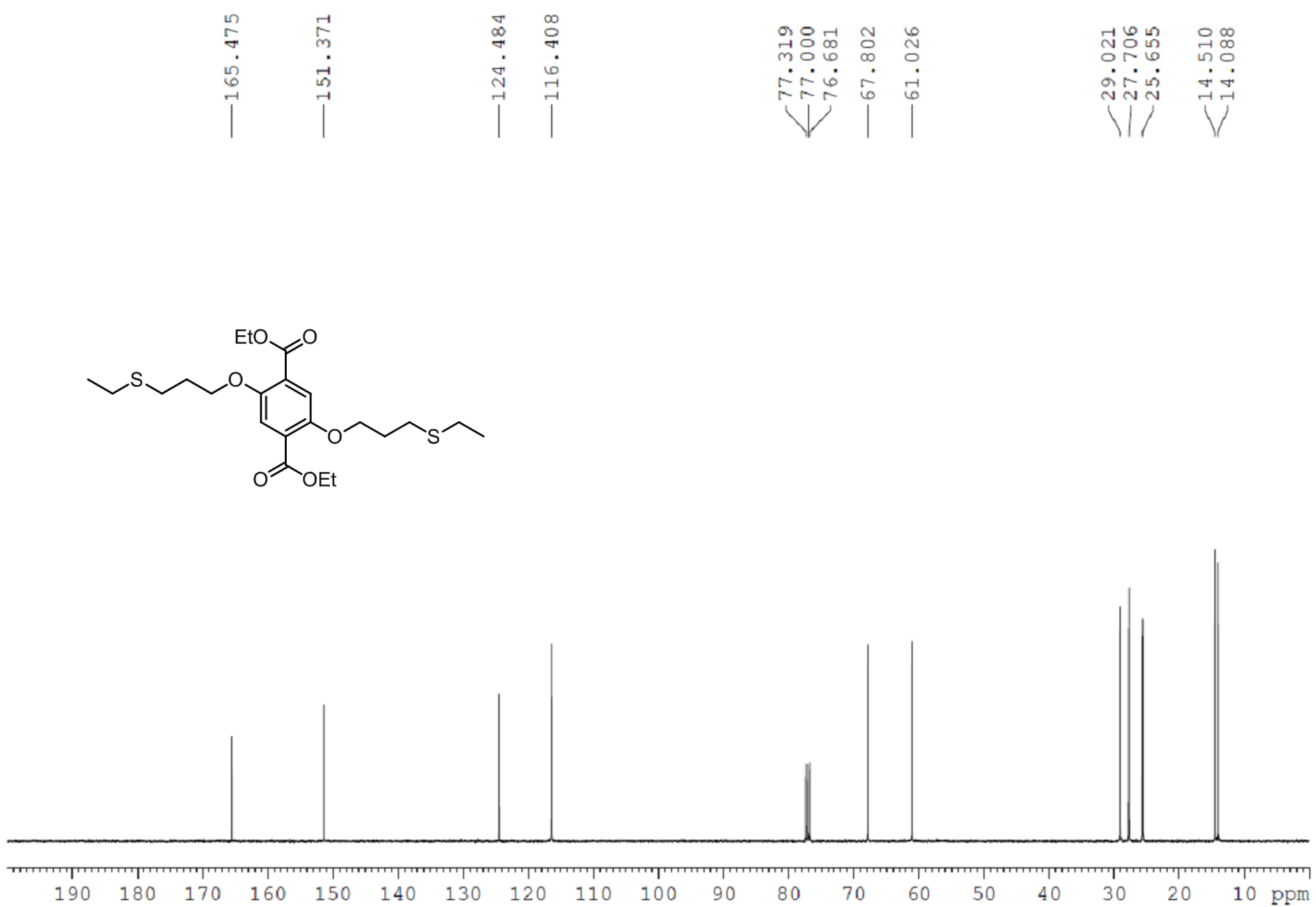


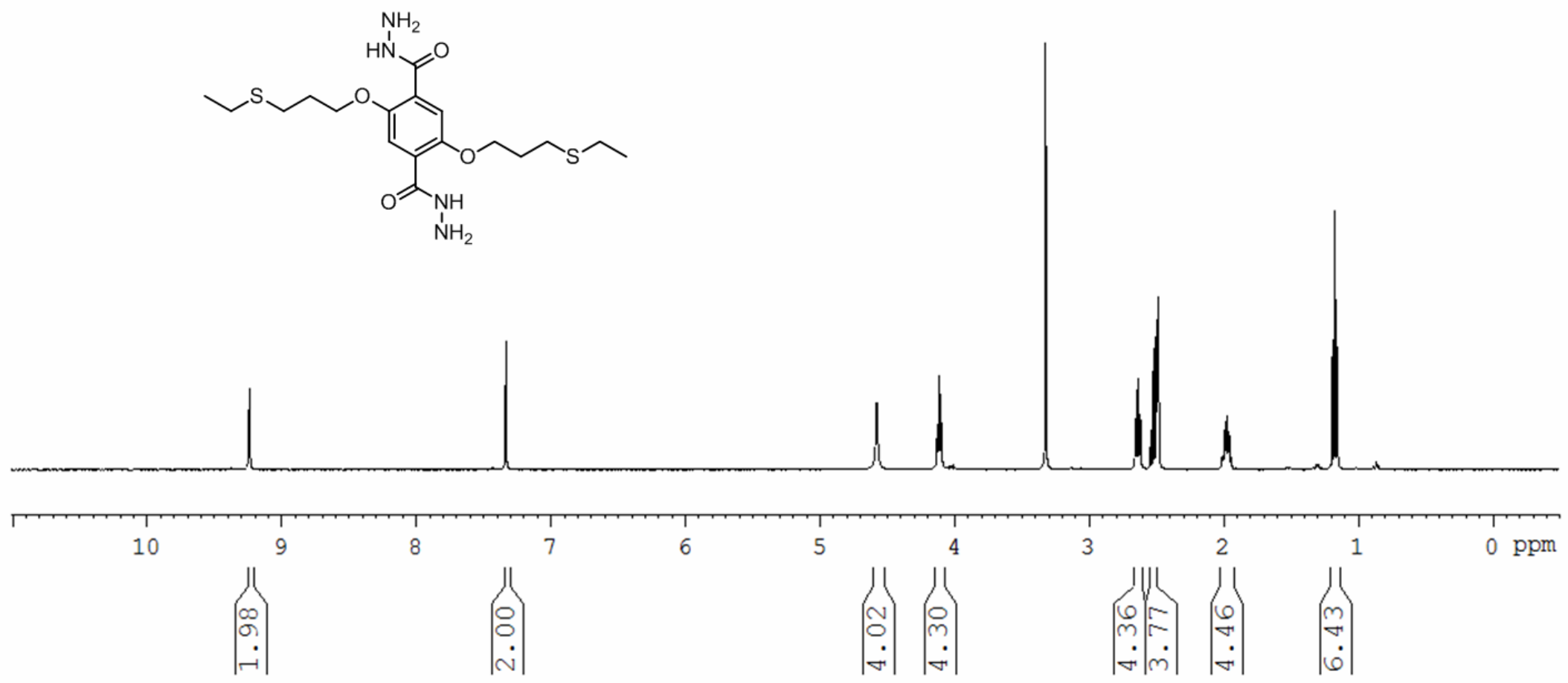



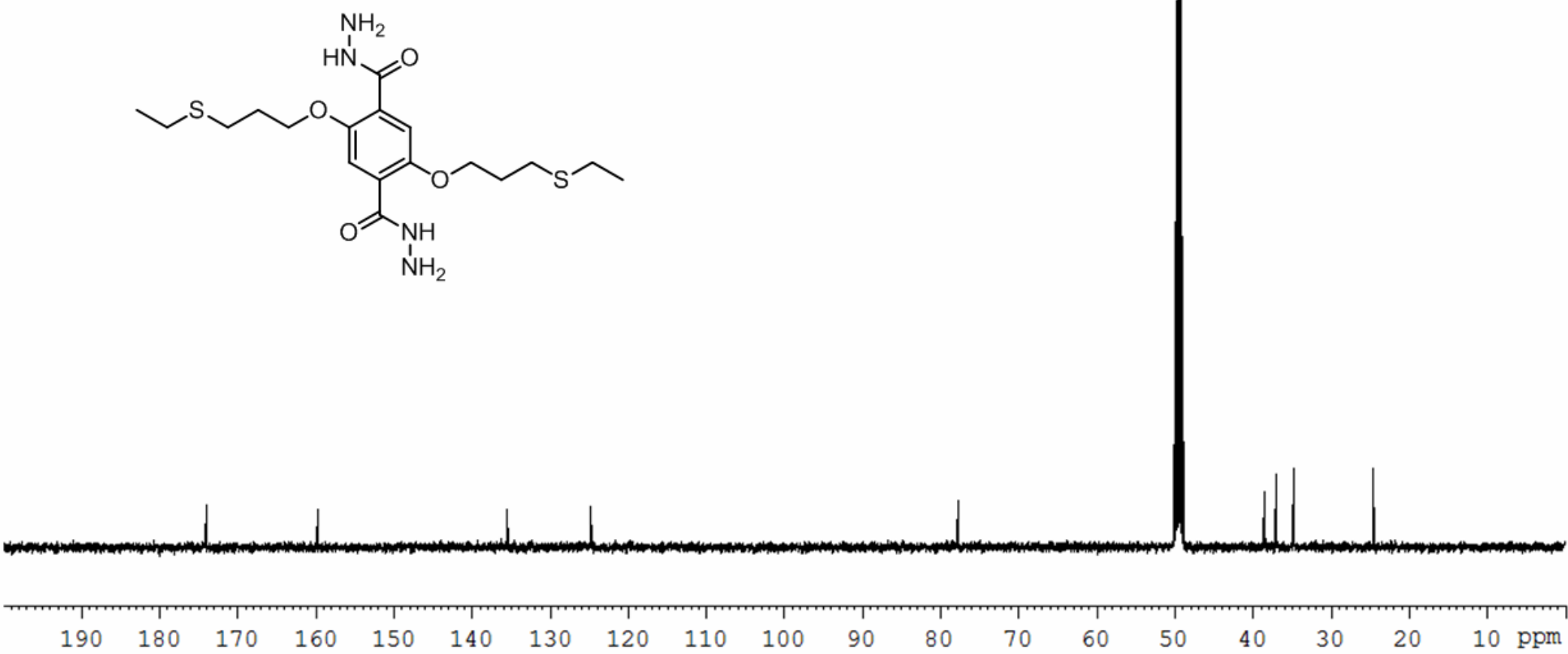


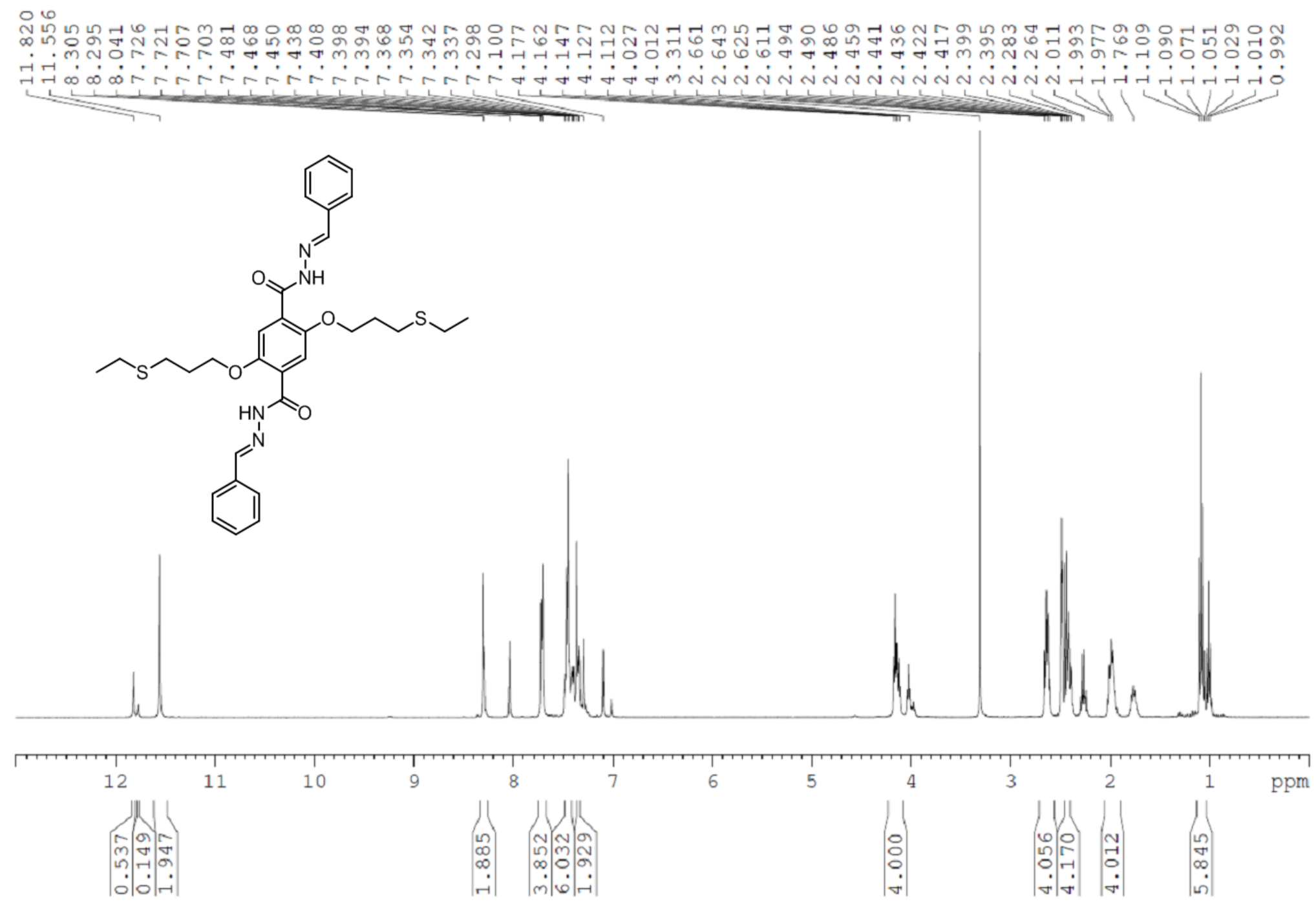




$$
+1
$$




\section{References}

1. Wrighton, M. S.; Ginley, D. S.; Morse, D. L., J. Phys. Chem. 1974, 78, 2229.

2. (a) Gole, B.; Bar, A. K.; Mukherjee, P. S., Chem. Commun. 2011, 47, 12137; (b) Sun, L.; Liang, Z.; Yu, J.; Xu, R., Polym. Chem. 2013, 4, 1932.

3. (a) Wu, D.; Huang, W.; Lin, Z.; Duan, C.; He, C.; Wu, S.; Wang, D., Inorg. Chem. 2008, 47, 7190; (b) Armstrong, R. D.; Porter, D. F.; Thirsk, H. R., J. Phys. Chem. 1968, 72, 2300; (c) Findlay, D. M.; McLean, R. A. N., Environ. Sci. Technol. 1981, 15, 1388; (d) Zhou, Y.; Zhu, C.-Y.; Gao, X.-S.; You, X.-Y.; Yao, C., Org. Lett. 2010, 12, 2566.

4. Itami, K.; Palmgren, A.; Thorarensen, A.; Bäckvall, J.-E., J. Org. Chem. 1998, 63, 6466.

5. Ding, S.-Y.; Gao, J.; Wang, Q.; Zhang, Y.; Song, W.-G.; Su, C.-Y.; Wang, W., J. Am. Chem. Soc. 2011, 133, 19816.

6. Uribe-Romo, F. J.; Doonan, C. J.; Furukawa, H.; Oisaki, K.; Yaghi, O. M., J. Am. Chem. Soc. 2011, 133, 11478.

7. (a) Long, G. L.; Winefordner, J. D., Anal. Chem. 1983, 55, 712A; (b) Hussain, S.; De, S.; Iyer, P. K., ACS Appl. Mater. \& Interfaces 2013, 5, 2234.

8. (a) Song, J.-R.; Sun, J.; Liu, J.; Huang, Z.-T.; Zheng, Q.-Y., Chem. Commun. 2014, 50, 788; (b) Yu, J.-T.; Chen, Z.; Sun, J.; Huang, Z.-T.; Zheng, Q.-Y., J. Mater. Chem. 2012, 22, 5369. 